University of Tennessee Health Science Center

UTHSC Digital Commons

\title{
$5-2014$
}

\section{Dopaminergic Genetic Contributions to Obesity in Kidney Transplant Recipients}

Ashley Grimes Stanfill

University of Tennessee Health Science Center

Follow this and additional works at: https://dc.uthsc.edu/dissertations

Part of the Nursing Commons

\section{Recommended Citation}

Stanfill, Ashley Grimes , "Dopaminergic Genetic Contributions to Obesity in Kidney Transplant Recipients" (2014). Theses and Dissertations (ETD). Paper 254. http://dx.doi.org/10.21007/etd.cghs.2014.0297.

This Dissertation is brought to you for free and open access by the College of Graduate Health Sciences at UTHSC Digital Commons. It has been accepted for inclusion in Theses and Dissertations (ETD) by an authorized administrator of UTHSC Digital Commons. For more information, please contact jwelch30@uthsc.edu. 


\title{
Dopaminergic Genetic Contributions to Obesity in Kidney Transplant Recipients
}

\begin{abstract}
Background: Kidney transplant recipients are a population who experience a high likelihood of gaining a significant amount of weight (between 6 and 13 kilograms) during the first year after transplantation. However, not all kidney transplant recipients gain weight. Studies have found little difference in physical activity and nutritional intake among those who do and do not gain weight. Immunosuppressant medications have also not been shown to play a substantive role in post-transplant weight gain. Additionally, although some studies have shown that age, gender, and race can influence weight gain, this information does not fully capture the observed variance. These observations suggest that genetic factors may have a role in the differential weight gain experienced by kidney transplant recipients. Dopamine is a neurotransmitter that has previously been implicated in substance addiction. Recently, neuroimaging and neurogenetic data have shown that dopamine may also play a role in obesity. Both dopamine receptor genes and genes related to overall dopamine activity have been associated with obesity, weight gain, and food addiction. Gene expression studies in subcutaneous adipose tissue of kidney transplant recipients showed that expression of some dopaminergic pathway genes was negatively correlated with weight gain. Polymorphisms in some of these genes have been linked to weight gain by others. Taken together, these results suggest that genetic variation in some dopaminergic genes may underlie changes in their expression or function and may contribute to the risk for gaining weight. The purpose of the proposed study was to determine if polymorphisms associated with these previously found dopaminergic genes have predictive value when combined with demographic characteristics to identify kidney transplant recipients who are at risk of gaining weight.
\end{abstract}

Methods: The subjects for this study represent a subsample of participants in a previous observational study. As a part of this study, age, race, and gender information were collected, as well as baseline and twelve month weight and height. Additionally, white blood cells were collected at baseline. Quantitative real time polymerase chain reaction (qPCR) and restriction fragment length polymorphism (RFLP) techniques were used to determine the genotype of these dopaminergic polymorphisms noted in previous work and in the literature as being related to weight gain. This included a total of 10 variants in 7 genes: dopamine receptor type 2 gene (DRD2) single nucleotide polymorphisms (SNPs) rs1800497, rs6277, and rs12364283, dopamine receptor type 3 gene (DRD3) SNP rs6280, dopamine receptor type 4 gene (DRD4) variable number tandem repeat (VNTR), catechol-o-methyltransferase gene (COMT) SNPs rs4680 and rs4818, monoamine oxidase A gene (MAOA) VNTR, monoamine oxidase B gene (MAOB) SNP rs1799836, and dopamine active transporter gene (SLC6A3/DAT1) VNTR. Genotypes were analyzed using dose dependent and risk allele approaches, and those variants with $p \leq 0.20$ were included in regression modeling. Regression models were built in a stepwise manner, first by building a model with only demographic characteristics, then by building a model with only genetic variants. Next, models were built with demographic and just individual genetic variants, and finally a model was built with demographic and all genetic variants included.

Results: Seventy subjects were included in this study (43\% female, 57\% African American, mean age 50.7 \pm 13.2 years). Age was found to be weakly correlated with percent weight change ( $r=-0.32)$, but race and gender showed no appreciable relationship to percent weight change at 12 months. A simple regression of age on percent weight change was significant $(p=0.006)$ and explained $11.2 \%$ of the variance. Multiple regression models of genetic and demographic factors explained between 11.4 and $25 \%$ of the variance, but no model reached statistical significance overall. However, age was consistently significant as a regressor. The SLC6A3/DAT1 9/10 genotype and the DRD2 rs1800497 TC genotype both approached significance in the modeling with $p$ values of 0.08 and 0.07 respectively. The DRD2 rs 1800497 genotype was also significantly correlated with percent weight gain in a dose dependent fashion $(r=-0.28, p=0.05)$. 
Conclusions: Increasing age is associated with less weight gain in the first year after kidney transplantation. Although the regression modeling failed to find significant association between weight gain and specific genotypes in the set of dopaminergic genes, this study was conducted as a pilot study to test the feasibility of the methodology. Even with the current sample size and effect size limitations, these results suggest that the DRD2 SNP rs1800497 and the SLC6A3/DAT1 VNTR have value in prediction of weight gain in kidney transplant recipients. To test the predictive value of these polymorphisms, further studies using a larger cohort of patients is required.

\section{Document Type}

Dissertation

Degree Name

Doctor of Philosophy $(\mathrm{PhD})$

\section{Program}

Nursing Sciences

\section{Research Advisor}

Donna Hathaway, Ph.D., R.N., F.A.A.N.

\section{Keywords}

Dopamine, Kidney transplant, Obesity, Weight gain

\section{Subject Categories}

Medicine and Health Sciences | Nursing 


\title{
DOPAMINERGIC GENETIC CONTRIBUTIONS TO OBESITY IN KIDNEY TRANSPLANT RECIPIENTS
}

\author{
A Dissertation \\ Presented for \\ The Graduate Studies Council \\ The University of Tennessee \\ Health Science Center
}

\author{
In Partial Fulfillment \\ Of the Requirements for the Degree \\ Doctor of Philosophy \\ From The University of Tennessee
}

\author{
By \\ Ansley Grimes Stanfill \\ May 2014
}


Copyright (C) 2014 by Ansley Grimes Stanfill. All rights reserved. 


\section{ACKNOWLEDGEMENTS}

I would like to acknowledge the members of my dissertation committee, without their guidance and wisdom I would never have been able to even dream of completing this project. Many, many thanks to Dr. Donna Hathaway, Dr. Yvette Conley, Dr. Ramin Homayouni, Dr. Patty Cowan, and Dr. Carol Thompson.

I would also like to thank Dr. Ann Cashion. I am forever grateful for her work as my advisor in the first year of my graduate program, and for her continued friendship. 


\begin{abstract}
Background: Kidney transplant recipients are a population who experience a high likelihood of gaining a significant amount of weight (between 6 and 13 kilograms) during the first year after transplantation. However, not all kidney transplant recipients gain weight. Studies have found little difference in physical activity and nutritional intake among those who do and do not gain weight. Immunosuppressant medications have also not been shown to play a substantive role in post-transplant weight gain. Additionally, although some studies have shown that age, gender, and race can influence weight gain, this information does not fully capture the observed variance. These observations suggest that genetic factors may have a role in the differential weight gain experienced by kidney transplant recipients. Dopamine is a neurotransmitter that has previously been implicated in substance addiction. Recently, neuroimaging and neurogenetic data have shown that dopamine may also play a role in obesity. Both dopamine receptor genes and genes related to overall dopamine activity have been associated with obesity, weight gain, and food addiction. Gene expression studies in subcutaneous adipose tissue of kidney transplant recipients showed that expression of some dopaminergic pathway genes was negatively correlated with weight gain. Polymorphisms in some of these genes have been linked to weight gain by others. Taken together, these results suggest that genetic variation in some dopaminergic genes may underlie changes in their expression or function and may contribute to the risk for gaining weight. The purpose of the proposed study was to determine if polymorphisms associated with these previously found dopaminergic genes have predictive value when combined with demographic characteristics to identify kidney transplant recipients who are at risk of gaining weight.
\end{abstract}

Methods: The subjects for this study represent a subsample of participants in a previous observational study. As a part of this study, age, race, and gender information were collected, as well as baseline and twelve month weight and height. Additionally, white blood cells were collected at baseline. Quantitative real time polymerase chain reaction (qPCR) and restriction fragment length polymorphism (RFLP) techniques were used to determine the genotype of these dopaminergic polymorphisms noted in previous work and in the literature as being related to weight gain. This included a total of 10 variants in 7 genes: dopamine receptor type 2 gene (DRD2) single nucleotide polymorphisms (SNPs) rs1800497, rs6277, and rs12364283, dopamine receptor type 3 gene (DRD3) SNP rs6280, dopamine receptor type 4 gene (DRD4) variable number tandem repeat (VNTR), catechol-o-methyltransferase gene (COMT) SNPs rs4680 and rs4818, monoamine oxidase A gene (MAOA) VNTR, monoamine oxidase B gene (MAOB) SNP rs1799836, and dopamine active transporter gene (SLC6A3/DAT1) VNTR. Genotypes were analyzed using dose dependent and risk allele approaches, and those variants with $p \leq 0.20$ were included in regression modeling. Regression models were built in a stepwise manner, first by building a model with only demographic characteristics, then by building a model with only genetic variants. Next, models were built with demographic and just individual genetic variants, and finally a model was built with demographic and all genetic variants included. 
Results: Seventy subjects were included in this study ( $43 \%$ female, $57 \%$ African American, mean age $50.7 \pm 13.2$ years). Age was found to be weakly correlated with percent weight change $(\mathrm{r}=-0.32)$, but race and gender showed no appreciable relationship to percent weight change at 12 months. A simple regression of age on percent weight change was significant $(\mathrm{p}=0.006)$ and explained $11.2 \%$ of the variance. Multiple regression models of genetic and demographic factors explained between 11.4 and $25 \%$ of the variance, but no model reached statistical significance overall. However, age was consistently significant as a regressor. The SLC6A3/DAT1 9/10 genotype and the DRD2 rs 1800497 TC genotype both approached significance in the modeling with $p$ values of 0.08 and 0.07 respectively. The DRD2 rs 1800497 genotype was also significantly correlated with percent weight gain in a dose dependent fashion $(\mathrm{r}=-0.28, \mathrm{p}=0.05)$.

Conclusions: Increasing age is associated with less weight gain in the first year after kidney transplantation. Although the regression modeling failed to find significant association between weight gain and specific genotypes in the set of dopaminergic genes, this study was conducted as a pilot study to test the feasibility of the methodology. Even with the current sample size and effect size limitations, these results suggest that the DRD2 SNP rs1800497 and the SLC6A3/DAT1 VNTR have value in prediction of weight gain in kidney transplant recipients. To test the predictive value of these polymorphisms, further studies using a larger cohort of patients is required. 


\section{TABLE OF CONTENTS}

CHAPTER 1. INTRODUCTION ......................................................................................1

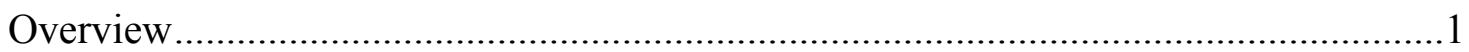

Purpose Statement and Aims ............................................................................... 3

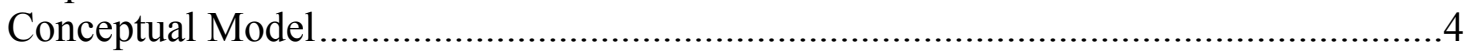

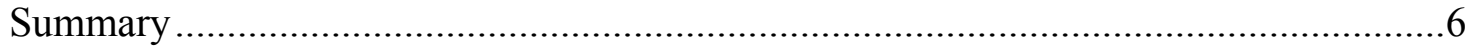

CHAPTER 2. REVIEW OF LITERATURE MANUSCRIPT ....................................7

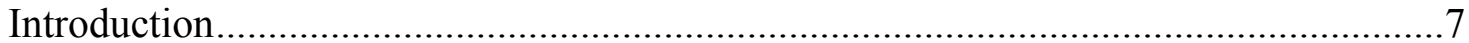

The Problem of Obesity ....................................................................................... 7

The Role of Dopamine........................................................................................... 7

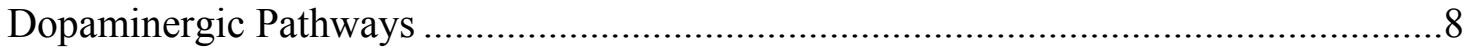

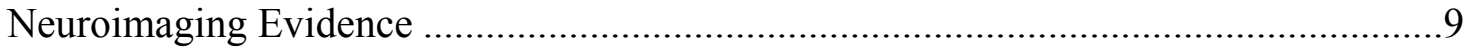

Genetic Evidence ....................................................................................... 10

Dopamine Receptor Genes ........................................................................... 10

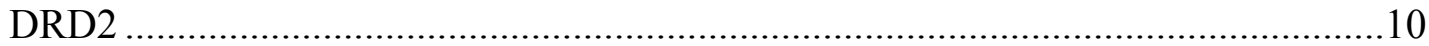

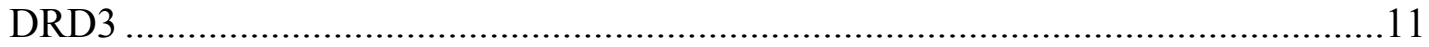

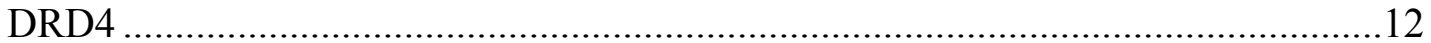

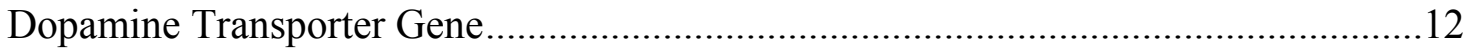

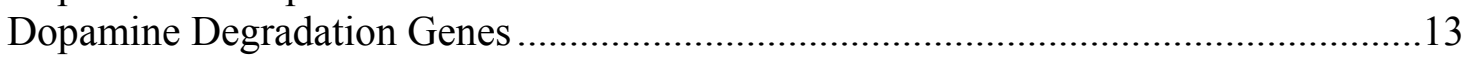

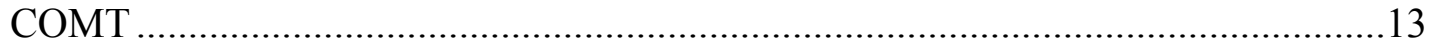

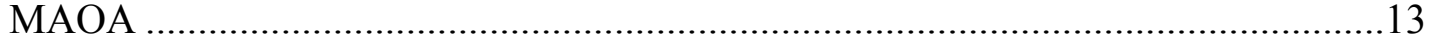

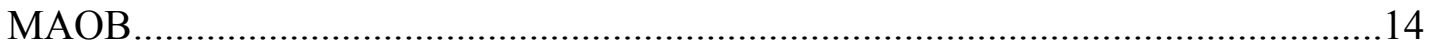

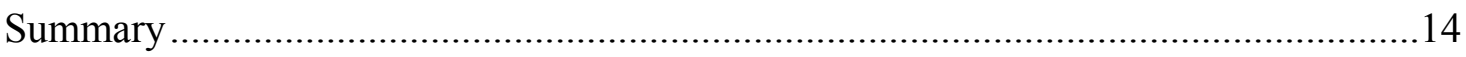

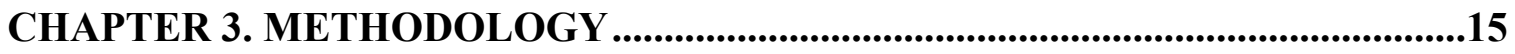

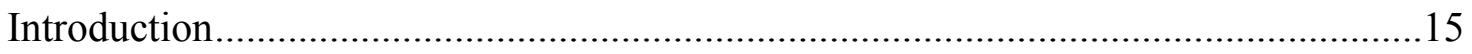

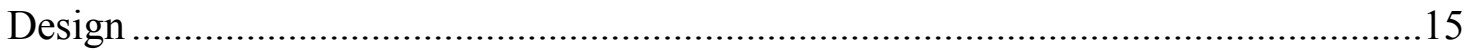

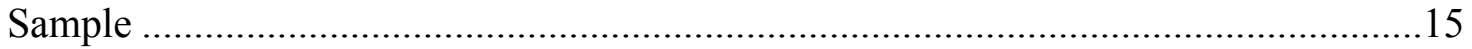

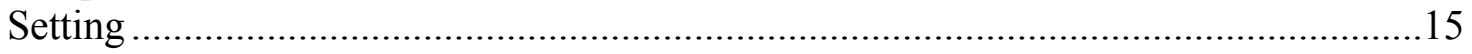

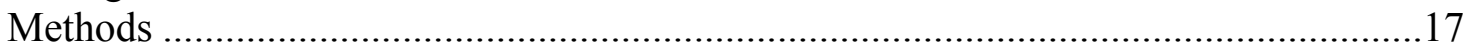

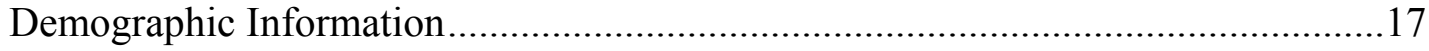

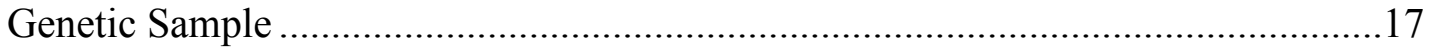

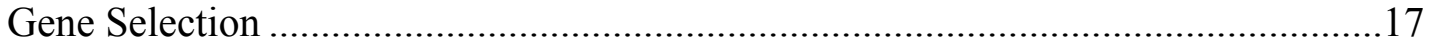

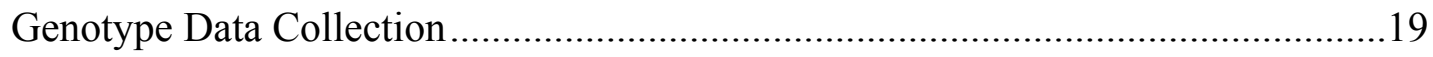

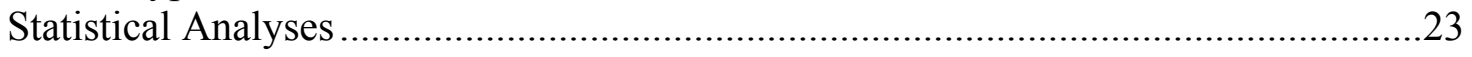

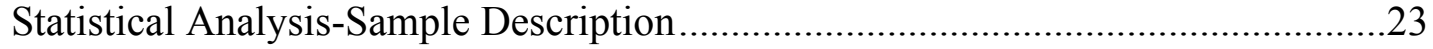

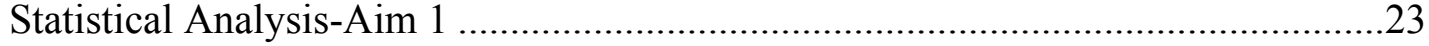

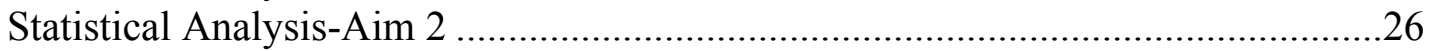

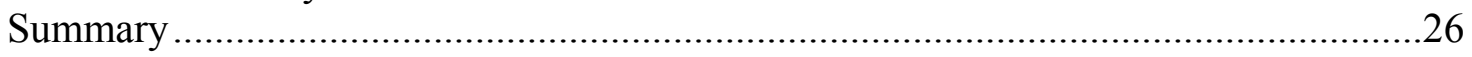




\section{CHAPTER 4. DEMOGRAPHIC AND DOPAMINERGIC GENETIC CONTRIBUTIONS TO OBESITY IN KIDNEY TRANSPLANT RECIPIENTS ...................................................................................27}

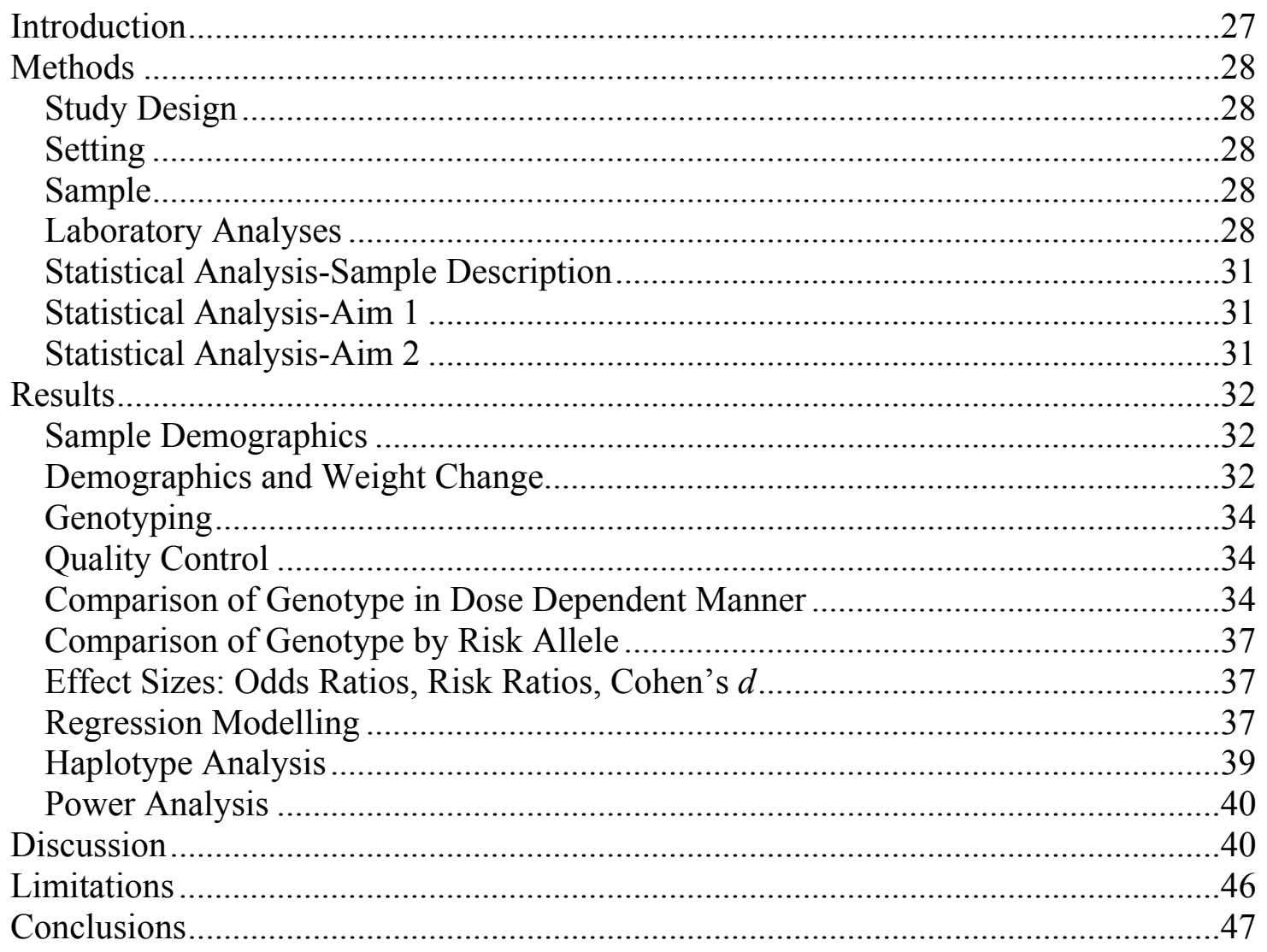

CHAPTER 5. IMPLICATIONS FOR PRACTICE AND FUTURE RESEARCH...48

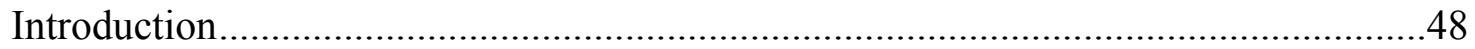

Modifications to Conceptual Model ..........................................................................48

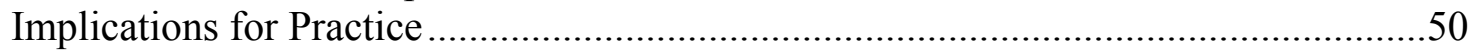

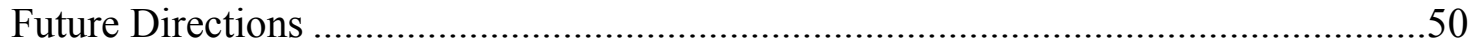

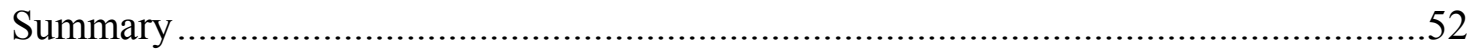

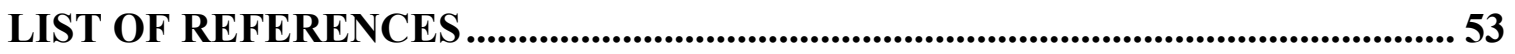

APPENDIX A. GENOTYPE DATA COLLECTION ..........................................61

APPENDIX B. INSTITUTIONAL REVIEW BOARD APPROVAL .....................66

VITA 


\section{LIST OF TABLES}

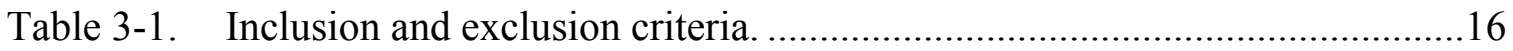

Table 3-2. NIH weight classification guidelines. ...................................................... 18

Table 3-3. Results from adipose tissue microarray study. ......................................18

Table 3-4. Dopaminergic single nucleotide polymorphisms.....................................21

Table 3-5. Dopaminergic variable number tandem repeats. ....................................22

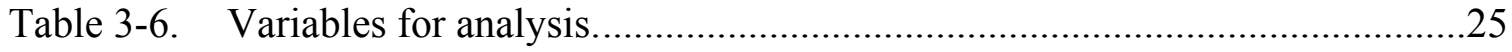

Table 4-1. $\quad$ Laboratory methods for dopaminergic SNPs and VNTRs. ........................29

Table 4-2. A comparison of demographic characteristics from the substudy and

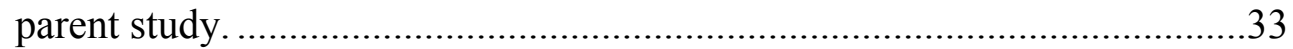

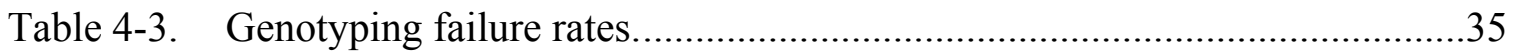

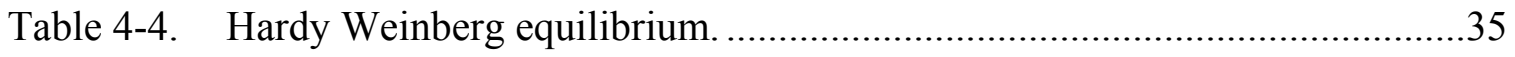

Table 4-5. Dose dependent comparison of genotype raw weight change in pounds. ....36

Table 4-6. Dose dependent comparison of genotype percent weight change. ...............36

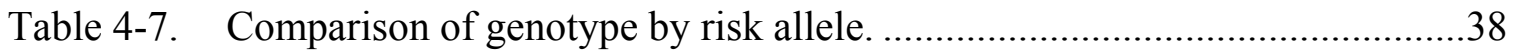

Table 4-8. $\quad$ Risk ratio, odds ratio, and effect size for each variant...............................38

Table 4-9. Post hoc power and sample size calculations. ........................................41

Table 4-10. Regression models for individual variants and demographic characteristics. 


\section{LIST OF FIGURES}

Figure 1-1. Conceptual model of post-transplant weight gain. ......................................5

Figure 3-1. IPA diagram showing dopaminergic pathway gene expression changes. ....20

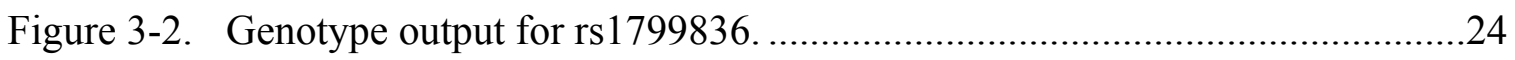

Figure 3-3. Selected lanes of DRD4 VNTR agarose gel used for genotyping...............24

Figure 4-1. Subject trendlines for BMI at baseline and twelve months' posttransplant.

Figure 5-1. Modifications to conceptual model...........................................................49 


\section{LIST OF ABBREVIATIONS}

\begin{tabular}{|c|c|}
\hline$\mu \mathrm{L}$ & Microliters \\
\hline A & Adenine \\
\hline AA & African American \\
\hline ADHD & Attention deficit hyperactivity disorder \\
\hline ANOVA & Analysis of variance \\
\hline BMI & Body mass index \\
\hline bp & base pairs \\
\hline${ }^{\circ} \mathrm{C}$ & Degrees Celsius \\
\hline $\mathrm{C}$ & Cytosine \\
\hline cAMP & Cyclic adenosine monophosphate \\
\hline COMT & Catechol-O-methyl transferase gene \\
\hline$d$ & Cohen's $d$ \\
\hline D2 & Dopamine receptor type 2 \\
\hline DAT1 & Dopamine active transporter 1 gene \\
\hline DMSO & Dimethyl sulfoxide \\
\hline DNA & Deoxyribonucleic acid \\
\hline DNTP & Dinucleotide triphosphates \\
\hline DOB & Date of birth \\
\hline $\mathrm{DRD} 2 / 3 / 4$ & Dopamine receptor type $2 / 3 / 4$ gene \\
\hline ENZ & Enzyme \\
\hline fMRI & Functional magnetic resonance imaging \\
\hline G & Guanine \\
\hline GABA & Gamma-aminobutyric acid \\
\hline Gly & Glycine \\
\hline GWAS & Genome wide association study \\
\hline IPA & Ingenuity pathway analysis \\
\hline $\mathrm{kb}$ & Kilobases \\
\hline $\mathrm{kg}$ & Kilogram \\
\hline Leu & Leucine \\
\hline M & Meter \\
\hline MAOA & Monoamine oxidase A \\
\hline MAOB & Monoamine oxidase B \\
\hline Met & Methionine \\
\hline $\mathrm{MgCl}_{2}$ & Magnesium chloride \\
\hline mRNA & Messenger ribonucleic acid \\
\hline NPY & Neuropeptide Y \\
\hline NPY1R & Neuropeptide Y receptor 1 \\
\hline NPY5R & Neuropeptide Y receptor 5 \\
\hline PCR & Polymerase chain reaction \\
\hline PET & Positron emission topography \\
\hline qPCR & Quantitative real time polymerase chain reaction \\
\hline RFLP & Restriction fragment length polymorphism \\
\hline RNA & Ribonucleic acid \\
\hline
\end{tabular}


SD

Ser

SLC6A3

SNP

$\mathrm{T}$

Taq

Taq $\alpha$

UTR

Val

VNTR
Standard deviation

Serine

Solute carrier family 6 , member 3 gene

Single nucleotide polymorphism

Thymine

Thermus aquaticus bacteria

Thermus aquaticus bacteria restriction enzyme alpha I

Untranslated region

Valine

Variable number tandem repeat 


\section{CHAPTER 1. INTRODUCTION}

The research presented in this document was undertaken to promote understanding of genetic contributions in dopaminergic genes to weight gain in kidney transplant recipients. The hypothesis tested in this study was that a combination of demographic and genetic variation in dopaminergic genes contributes to the risk of weight gain following kidney transplantation. Once identified, these individuals could then be targeted with personalized lifestyle interventions aimed at reducing weight gain.

\section{Overview}

Approximately one third to one half of all kidney transplant recipients gain weight during the first year after surgery (Baum, 2001; Cashion et al., 2007). For many of these individuals, this weight gain can be substantial, with averages reported of between 6 and 13 kilograms (Cashion et al., 2007; Patel, 1998). While weight can cause psychological damage such as depression, it also places individuals at increased risk of comorbidities such as cardiovascular disease and diabetes (Baum, 2001). In fact, the number one cause of death for kidney transplant recipients is not graft failure, but rather cardiovascular disease (Baum, 2001; Faravardeh et al., 2013).

However, not all kidney transplant recipients gain weight. Several studies have attempted to examine differences between those who do and do not gain weight following organ transplantation surgery, but these studies have not yet been able to adequately explain the variation seen. A lack of physical activity and excessive intake of calories is often the source of weight gain, but little difference has been observed in these variables for the kidney transplant population (Cashion et al., 2014; Cupples et al., 2012). Certain demographic characteristics (age, race, gender) have been found to explain a small amount of the variance shown in weight gain. For example, older African American women are the most likely to gain weight after transplantation. Still, these demographic variables alone do not fully explain who will and will not gain weight (Cashion et al., 2007). Furthermore, immunosuppressant therapy related to the organ transplant has not been found to play a major role in weight gain following transplant surgery (Elster et al., 2008; van den Ham, Kooman, Christiaans, Nieman, \& van Hooff, 2003; Woodle et al., 2008).

It has been shown that variations in genotype may predispose certain individuals to exhibit an increased body mass index, and to gain weight (Bauer et al., 2009; Frayling et al., 2007; Willer et al., 2009). It therefore seems likely that individual genetic factors may also account for the weight gain experienced by some transplant recipients. These variations (polymorphisms) can fall into several categories, but most common are single nucleotide polymorphisms (SNPs) and repetitive DNA polymorphisms, such as variable number tandem repeats (VNTRs). These types of polymorphisms can impact the amino acid sequence of a protein, the amount of protein made, or the stability of mRNA, resulting in an altered product that predisposes that individual to weight gain. 
Alternatively, if the polymorphism is located in the promoter region of the gene, it could turn on or off the activity of that gene entirely. This could result in a many fold change to the normal levels of the protein product. Still other polymorphisms have no functional consequences at all, but serve as markers for genetic studies in which the association is with a section of DNA containing the variant.

While many genes can have these various types of changes, the alterations in the neurotransmitter dopamine have recently gained the attention of obesity researchers. Dopamine plays a role in many behaviors, but is most commonly associated with reward pathways in the brain. Normally, dopamine release is responsible for the pleasant feelings associated with the consumption of palatable food (Abizaid, Gao, \& Horvath, 2006).

Once released, the neurotransmitter binds to specific receptors and is eliminated from the synaptic cleft by degradation enzymes and reuptake proteins. Polymorphisms in these closely related genes could cause increases or decreases in the receptor's affinity for dopamine (Jeanneteau et al., 2006), or change the rate at which dopamine is inactivated after release. Individuals that possess these genetic changes can then have varying degrees of dopaminergic system dysfunction. In these people, it may take more of a stimulus (i.e., overeating) to create a rewarding response to food. Perhaps those with dopaminergic system dysfunction may select different, for example fattier or sweeter foods, to increase the activity of the dopamine they have available (Baik, 2013).

Both dopamine receptor genes and genes related to overall dopamine activity have been associated with obesity, weight gain, and food addiction (Volkow, Wang, \& Baler, 2011). Neuroimaging (Carnell, Gibson, Benson, Ochner, \& Geliebter, 2012; Michaelides, Thanos, Volkow, \& Wang, 2012; Volkow, Wang, Fowler, \& Telang, 2008) and neurogenetic (Blum, Liu, Shriner, \& Gold, 2011; Heber \& Carpenter, 2011; Need, Ahmadi, Spector, \& Goldstein, 2006) data have also confirmed these associations.

These same associations hold true in the kidney transplant population as well. Gene expression analysis of adipose tissue showed that expression levels of 1553 genes (1936 probes) were significantly $(\mathrm{p} \leq 0.05)$ associated with relative weight change at 6 months (Cashion et al., 2013). These genes included the dopamine receptor genes DRD2, DRD3, and DRD4, the dopamine degredation genes MAOA, MAOB, and COMT, and the dopamine transporter SLC6A3/DAT1 (Cashion et al., 2013). This work confirms an involvement of dopamine pathways in weight gain for the kidney transplant population (Cashion et al., 2013).

Some of these dopaminergic genes have polymorphisms that may impact gene regulation and place these individuals at risk for gaining weight. Genotype data could potentially also be combined with demographic characteristics to predict who will and who will not weight gain in the kidney transplant population. 


\section{Purpose Statement and Aims}

Research to date suggests that multiple factors act as covariates to directly or indirectly influence changes in weight following transplantation. For this study, the demographic characteristics of age, race, and gender were selected because they were found to be important in the literature (Cashion et al., 2007; Clunk, Lin, \& Curtis, 2001). The genes were selected not only for their importance in the literature, but also because their expression levels were associated with weight gain in studies conducted on a small sample of these same kidney transplant recipients (Cashion et al., 2013). The current study will lay the foundation for future work that will more fully explicate these relationships. The purpose of this study is to determine if there is an association between polymorphisms of selected dopaminergic genes, demographic characteristics, and the amount of weight gained one year after kidney transplantation. The specific aims of this research are to:

- evaluate the ability of polymorphisms in a subset of dopaminergic genes to predict weight gain in kidney transplant recipients.

- determine the interaction of genetic polymorphisms in the subset of dopaminergic genes with demographic characteristics (age, race, and gender) and their combined ability to predict weight gain in a kidney transplant population.

This work addresses a critical barrier in the field of obesity research and kidney transplantation. While much research has been done on the genetic factors related to obesity, the relationship between behavioral genetics and obesity is just beginning to be explored. This work moves obesity research forward by providing information on contribution of polymorphisms in dopaminergic genes to weight gain in a well-defined population with which to study weight gain.

This project expands upon our own work, and adds to the scientific knowledge about the role of dopaminergic genes in weight gain. It also adds to the understanding of the influence that demographic characteristics have on the phenotype predicted by a genotypic profile. This study may inform clinical practice in kidney transplant and obese populations in general, by increasing awareness of the factors influencing weight gain and obesity. Long term, it may also influence the development of clinical genetic testing as a screening tool to identify patients at risk for weight gain in clinical populations. Understanding the biological underpinnings of weight gain after transplantation can also help to create more effective interventions to improve health and wellbeing after the surgery. 


\section{Conceptual Model}

The conceptual model for this study hypothesizes a relationship among environmental factors, dopaminergic genetic profile, and the outcome of post-transplant weight gain for kidney transplant recipients.

This model is shown in Figure 1-1. The model is illustrated as a wheel with broken boundaries to indicate the interaction among spokes of the wheel, similar to the model proposed by Ziauddeen (Ziauddeen, Farooqi, \& Fletcher, 2012). The categories themselves have been altered from the original model to reflect the uniqueness of the kidney transplant population.

On the right side of the wheel, the environmental factors of physical activity, diet, and medication are shown. Certainly, physical activity and diet have been shown to reduce weight and also reduce the risk of comorbidities commonly associated with obesity (for an excellent review, see (Swinburn, Caterson, Seidell, \& James, 2004)). In transplant populations, immunosuppressant therapy (including treatment with prednisone) is also often blamed for weight gain after surgery. However, these regions of the wheel have been shaded to indicate factors that have not been shown to have significant influence in this particular sample. While it is true that in general, environmental factors such as physical activity, and diet (gross caloric intake) are thought to play a role in weight change, in our sample there is insufficient variability in any of these factors to explain the differential weight gain observed (Cupples et al., 2012). Additionally, our subjects were on similar immunosuppressant protocols, and others have shown immunosuppressant therapy does not have a substantive effect on the amount of weight gained after transplantation (van den Ham et al., 2003; Woodle et al., 2008). This homogeneity can be considered a strength of this study population as these environmental influences are minimized. Thus, our kidney transplant sample is ideal for this type of genetic study as there is a broad variability in phenotype without the confounding influences of physical activity and dietary environmental factors.

Race, gender, and age are demographic characteristics that may influence weight gain in this population. Previous studies in the kidney transplant population have shown that African American women are more likely to be classified as obese at one year after transplantation, although race and gender do not explain the total variation seen (Cashion et al., 2007). Large epidemiological studies have shown that people tend to gain weight as they age, with weight peaking at late middle age (Cornoni-Huntley et al., 1991; Yarnell, Patterson, Thomas, \& Sweetnam, 2000). Most of the patients in our sample have their surgery in late middle age, thus increasing the risk of weight gain. Therefore, race, gender, and age are considered as covariates along with other factors in weight gain.

The box on the left of the model illustrates the dopaminergic genetic contributions to weight gain and obesity. These genes were selected due to their previous association as reported in the literature, but also due to their association in previous work in kidney transplant recipients (Cashion et al., 2013). Each gene depicted has various polymorphisms that influence the dopamine levels in the brain through either overall 


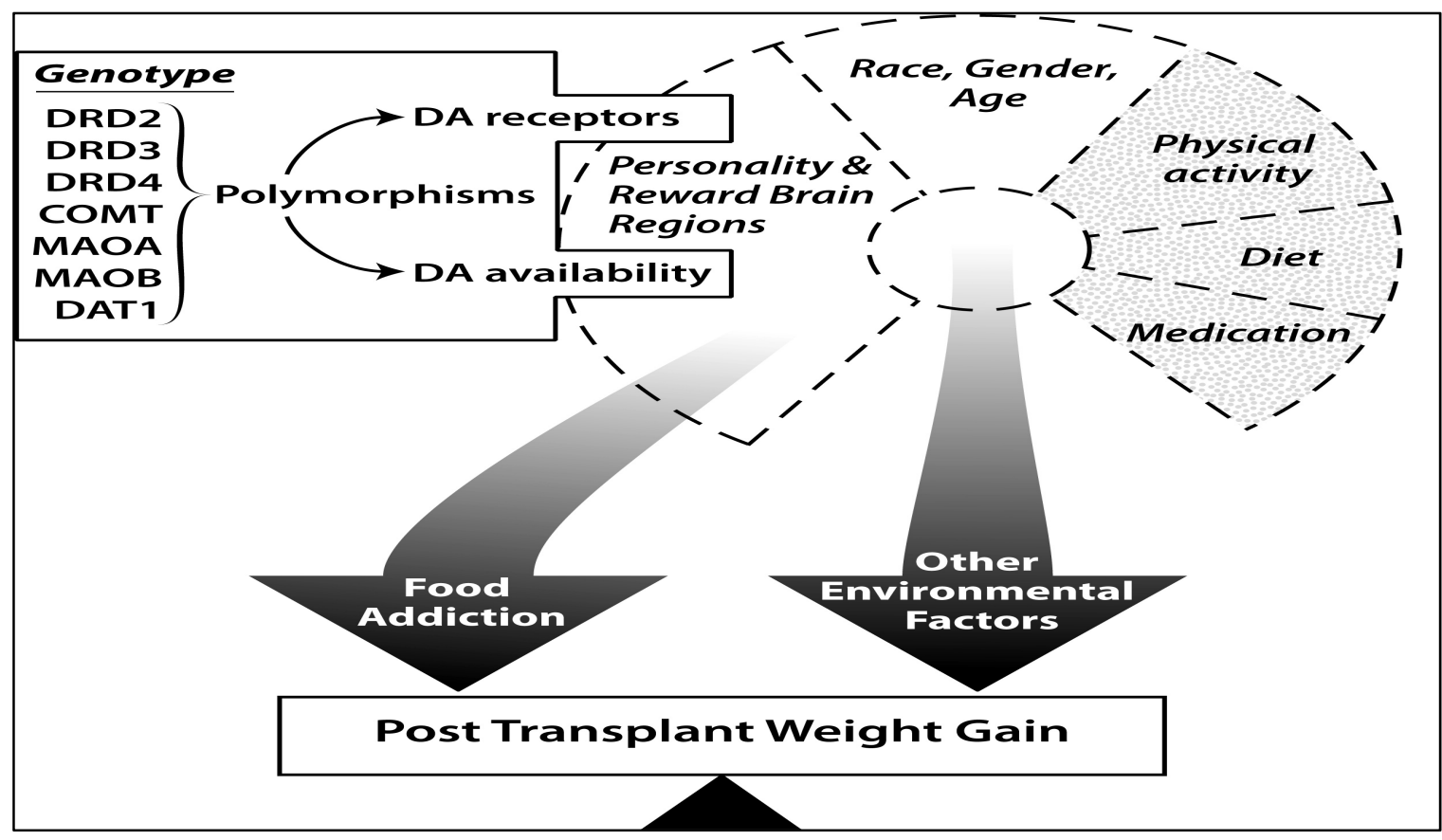

Figure 1-1. Conceptual model of post-transplant weight gain. 
bioavailability of the neurotransmitter, through dopamine transport alterations, or through regulation of dopamine receptors. It is widely known that binding of dopamine to its receptor sites induces a pleasurable feeling, and this binding is responsible for some of the rewarding experience that occurs when eating highly palatable food (Wise, 2008). If dopamine or its receptors are more widely available, this can increase the binding rate. Additionally, alterations within the transport system can cause alterations in the binding rate, depending on whether the dopamine is more likely to be transported into the postsynaptic neuron or undergoing reuptake into the presynaptic neuron.

It is the synergistic effect of all spokes of the wheel, acting in concert as environmental factors, that have an impact on the outcome of post-transplant weight gain; exerting more or less influence on the gain or loss of weight. This influence may be viewed as working in counterbalance to the influence imposed by the genetic side of the model. Together environmental and food addictive behavior act as complementary forces indicated by the arrows to influence post-transplant weight gain in a dynamic fashion.

\section{Summary}

In summary, this chapter has provided an introduction to the proposition that dopaminergically driven changes in weight post kidney transplant, and a brief overview of experimental evidence to support this hypothesis. This chapter discussed the purpose and aims of the study and a proposed conceptual model for the development of obesity in kidney transplant recipients. Chapter 2 will present a review of literature on why obesity is problematic, and the biological basis for how dopamine influences weight gain. This review will have a particular emphasis on the neurogenetic and neuroimaging evidence that relates the changes in dopamine production to changes in weight. Chapter 3 reviews the methodology used for this study, while Chapter 4 is presented in manuscript format and provides the results and conclusions of the study along with a review of the background and study methods. Finally, Chapter 5 provides evidence based modifications to the conceptual model presented here, and suggests future directions for clinical and research practice. 


\section{CHAPTER 2. REVIEW OF LITERATURE MANUSCRIPT}

\section{Introduction}

As the incidence of obesity continues to rise, clinicians and researchers alike are seeking explanations for why some people become obese while others don't. One theory is that some individuals may have alterations in the neurotransmitter dopamine. These alterations can cause them to have a disordered experience with the rewarding properties of food. This review of literature examines the extant knowledge about the relationship between obesity and the dopaminergic reward pathways in the brain, with evidence from both neuroimaging and neurogenetic data.

\section{The Problem of Obesity}

According to the Centers for Disease Control, between 2007 and 2009, the incidence of obesity in America increased 1.1\% (Centers for Disease Control and Prevention) netting an additional 2.4 million Americans who met the criteria for obesity (body mass index (BMI) of greater than $30 \mathrm{~kg} / \mathrm{m}^{2}$ ). This increase is of concern as obesity is a modifiable risk factor that has a strong correlation with various comorbidities, including cardiovascular disease and diabetes. In fact, obesity (associated with poor diet and lack of physical activity) is one of the leading causes of death in the United States (Mokdad, Marks, Stroup, \& Gerberding, 2004). Cultural and social factors most certainly play a role in the development of obesity, but individual elements determine who will or will not become obese in a given situation.

Usually, weight gain leading to obesity is attributed to an intake of calories in excess of what is used in metabolism and physical activity. Traditional weight loss plans have had great (if often temporary) success with reductions in the intake of food and increasing the amount of calories expended in exercise. However, these diet plans do not work for many people. In some cases, the person experiences a "yo-yo diet", where they stay on the plan for a while and lose weight, but quickly regain it only to start the cycle over again. Some researchers have suggested that those who have extreme difficulty in long term weight management may be genetically different than other individuals. While obesity is most certainly a polygenic disorder, some of these genetic differences may revolve around the reward neurotransmitter dopamine.

\section{The Role of Dopamine}

Dopamine has long been thought to be a neurotransmitter that is relevant to the study of obesity. Although many other neurotransmitters (such as GABA, glutamine, serotonin, and norepinephrine) can play a role in food intake, dopamine has been most often directly implicated in food reward from experimental evidence (Tomkins \& Sellers, 2001). 
Olds and Milner's classic experiments first showed the world that rats will obsessively press a lever for stimulation to the dopaminergic reward centers of their brains (Olds \& Milner, 1954). This was the first suggestion that the release of dopamine in the brain is associated with pleasurable feelings.

Food intake is also associated with the release of dopamine, thus giving the pleasant feelings associated with eating (Baik, 2013). In individuals with normal functioning of their dopaminergic systems, even a brief cue, such as smell or sight, of a familiar food can begin the release process (Schultz, 1998). Once these cues are noted, the whole experience of eating is perceived by the dopaminergically normal person as being pleasurable. In particular, highly palatable foods, such as those with higher sugar and fat content, stimulate the dopaminergic pathways more than less palatable foods (Baik, 2013).

Some of these pleasurable feelings from the dopamine release can lead to a feeling of satiety after food is consumed. This supposition is supported by the observation that if dopamine release is blocked chemically, the person reports an increase in appetite (Barry, Clarke, \& Petry, 2009). This chemical block occurs clinically when patients are placed on anti-psychotic medications, which are often associated with weight gain (Allison et al., 1999). Alternatively, when levels of synaptic dopamine are increased, appetite decreases. This also occurs clinically when patients are placed on certain medications for attention deficit hyperactivity disorder, and is thought to be related to blockage of the dopamine active transporter 1 gene (DAT1) (Capp, Pearl, \& Conlon, 2005). Furthermore, the relationship between dopamine levels and changes in eating behavior has been shown in laboratory animals. "Dieting" rats (modeled by time sensitive restriction to sucrose) have alterations in dopamine levels, receptors, and transport mechanisms, as compared to those with unrestricted access (Bello, Lucas, \& Hajnal, 2002; Bello, Sweigart, Lakoski, Norgren, \& Hajnal, 2003; Hajnal \& Norgren, 2002).

Thus, any disruption in the balance of the dopaminergic system can result in disordered eating patterns. Consequently, individuals with alterations in their dopaminergic systems overeat to raise their dopamine levels in an attempt to derive a pleasurable feeling from food. Subsequently, as this overeating continues over time, these individuals develop an insensitivity to the pleasurable feeling due to chronic overstimulation of the dopaminergic pathways (Barry et al., 2009). Although counterintuitive, the hypothesis is that the overeating is compensating for a reduced dopaminergic response (Volkow, Wang, Tomasi, \& Baler, 2013). Long term, overconsumption then leads to weight gain and to the development of obesity.

\section{Dopaminergic Pathways}

Dopamine is present throughout the brain, but it is concentrated in four major pathways: the nigrostriatal pathway, tuberoinfundibular pathway, the mesolimbic pathway, and the mesocortical pathway. The nigrostriatal pathway runs from the substantia nigra to the striatum, and it is mostly responsible for movement. When 
portions of this pathway are dysfunctional, this disturbance results in Parkinson's Disease. The second pathway, the tuberoinfundibular pathway, includes dopaminergic projections in the hypothalamus and the pituitary gland, and it is important for development and regulation of the hormone prolactin. Although neither of these pathways has been shown to be strongly associated with obesity, the mesolimbic and mesocortical have been. These pathways are known as the "reward pathways", and include dopaminergic regions related to impulsivity, self-control, and the pleasurable feelings associated with addictive behaviors.

Dopamine's association with obesity first begins in the mesolimbic pathway. This pathway begins in the ventral tegmental area and projects to the nucleus accumbens. These areas are in the midbrain, and are outside our conscious control. But it is known that in response to hunger cues (driven by hormones such as ghrelin, leptin, and insulin), the activity of dopaminergic neurons in the ventral tegmental area is increased (Opland, Leinninger, \& Myers, 2010). The other pathway, the mesocortical pathway, projects from the ventral tegmental area to the higher reasoning centers of the cerebral cortex that control reward and motivation. Oftentimes, the two pathways are combined and referred to as the mesolimbocortical pathway because of the close interplay of reward mechanisms and pleasurable feelings. Overall, the mesolimbocortical pathway has been found to be associated with many types of rewarding experiences, but is most strongly associated with fundamental pleasures, such as sex and food, and less strongly associated with higher order pleasures, such as monetary, altruistic, and artistic pleasures (Kringelbach \& Berridge, 2010).

\section{Neuroimaging Evidence}

Neuroimaging provides an important tool to the study of obesity because of its ability to localize different areas of the brain involved in eating behavior. In particular, fMRI data is valuable in that it can display areas of increased blood flow (i.e. areas that are activated) during particular tasks. For instance, the insula and the striatum are commonly co-activated during presentation of food cues (Tang, Fellows, Small, \& Dagher, 2012). The amygdala has also been shown to be activated during eating, perhaps due to the associated positive emotions. Additionally, the activation of prior memories and experience with food is believed to activate the hippocampus (Carnell et al., 2012). Neuroimaging also allows comparisons of activation patterns between obese and normal weight individuals while being presented food cues. From this, we know that obese individuals show greater activation in the mesolimbocortical pathway than normal weight individuals (Killgore \& Yurgelun-Todd, 2005).

Another type of neuroimaging uses a variation of the traditional PET scan to identify dopaminergic activity and dopamine receptors. For example, one study using this technology has shown that dopamine release correlates with the ratings of pleasantness experienced during food consumption (Small, Jones-Gotman, \& Dagher, 2003). Another study found that when subjects were presented with food cues, increases in dopamine were correlated to the level of hunger reported by subjects (Volkow et al., 2002). Studies 
of this type confirm that there are lower levels of dopamine receptors in the striatum of obese patients, such that the magnitude of the reduction is proportional to the increase in BMI (Haltia et al., 2007; G. J. Wang et al., 2001). This may reflect a reduction in the rewarding aspects of food intake, perhaps causing overeating in compensation. Another study has shown that the reduction in dopamine receptors relates to decreased activity in the prefrontal cortex, which may reflect a reduction in the self-control over intake in obese individuals (Volkow et al., 2008).

Neuroimaging has also demonstrated an overlap between obesity and substance addiction, prompting the hypothesis that a type of food addiction may play a role in the development of obesity. This overlap is intuitive, as many commonly abused substances act on the dopaminergic pathways in much the same way that highly palatable food does. An overlap in the activation patterns has also been shown for smoking (Tang et al., 2012), cocaine, heroin, alcohol, and methamphetamine, with reductions in the number of dopamine receptors and in the amount of dopamine released in addicted individuals (Martinez et al., 2005; Volkow, Fowler, Wang, \& Swanson, 2004; Volkow et al., 1997). This overlap is especially true for the striatum, the prefrontal cortex (Tomasi \& Volkow, 2013), and the hippocampus (Michaelides et al., 2012).Interestingly, obese individuals are less likely to use illicit drugs (Bluml et al., 2012) and if they do, are at less risk for a substance use disorder in the future (Simon et al., 2006). This could indicate that obese individuals are already achieving, by overeating, the reward that many drug users seek.

\section{Genetic Evidence}

Genetic evidence supporting the relationship between dopamine and obesity comes from dopamine receptor genes, dopamine transport genes, and genes involved in dopamine degradation. Alterations at any of these points in the pathway can change the levels of dopaminergic stimulation in the brain.

\section{Dopamine Receptor Genes}

The dopamine receptor genes most widely implicated in obesity are dopamine receptor D2 (DRD2), dopamine receptor D3 (DRD3), and dopamine receptor D4 (DRD4). All of these receptors have seven transmembrane domains and are G-protein coupled receptors. These three receptors are also classified as D2-like receptors, meaning that they inhibit intracellular cAMP to suppress that signaling pathway (Baik, 2013).

\section{DRD2}

D2 receptors are the most abundant type of dopamine receptor in the brain (Baik, 2013). An allele for a functional polymorphism (rs1800497, Taq1A) has been shown to be correlated with an overall reduction in the number of D2 receptors in the brain (Jonsson et al., 1999; Pohjalainen et al., 1998). Individuals carrying this allele have a 
reduction in the rewarding aspects of eating, and it has been associated with an overall "reward deficiency syndrome". This syndrome is a multi-substance or multi-high risk activity abuse seen in those lacking proper dopamine function (Blum, Liu, et al., 2011; Noble et al., 1998). The reduction in reward processing for people with this genotype has been confirmed by neuroimaging data (Pecina et al., 2012) and has been shown to be associated with an overall higher BMI (Jenkinson et al., 2000). The reduction in DRD2 receptors has also been shown as being proportional to the increase in BMI (G. J. Wang et al., 2001).

Moving down the DRD2 gene by roughly $17 \mathrm{~kb}$, another polymorphic site in the DRD2 gene called C957T (rs6277) also has effects on the function of the dopamine receptor. The T allele (versus $\mathrm{C}$ ) is associated with reduced levels of DRD2 mRNA overall, and also reduced translation of that mRNA into receptor protein (Duan et al., 2003). This reduction has been confirmed by PET to result in lower levels of D2 receptors in the striatum of individuals with this allele, and the receptors that are present show lower binding affinity for dopamine (Hirvonen et al., 2004). When this allele is combined with the influence of the Taq1A allele and age, it explains $40 \%$ of the variance in the numbers of dopamine D2 receptors throughout the brain (Hirvonen et al., 2004).

Another $63 \mathrm{~kb}$ down the gene, rs 12364283 is in a conserved suppressor region (Y. Zhang et al., 2007). Not surprisingly, when this area is disturbed by the change into the minor $\mathrm{T}$ allele, the result is increased transcription and receptor density (Y. Zhang et al., 2007). This is especially interesting, as it helps to support the results seen by the authors in a previous study. To summarize, RNA expression changes in five genes related to dopamine secretion were found to be associated $(p=0.0004)$ with weight gain at six months' post-transplant (Cashion et al., 2013). Based on this evidence, it is logical to infer that the expression changes seen in RNA could be created by variations in the regulatory regions in DNA for those genes.

\section{DRD3}

The functional Ser9Gly polymorphism (rs6280), located within the DRD3 gene on the long arm of chromosome 3, has been associated with increased dopamine affinity (Lundstrom \& Turpin, 1996). Specifically, the gly allele causes dopamine to have an affinity for its receptor that is five times higher than the ser allele (Jeanneteau et al., 2006). Heterozygosity for this polymorphism is associated with higher scores on impulsiveness (Limosin et al., 2005). Clinically, the gly allele has been associated with smoking (Huang, Payne, Ma, \& Li, 2008), as well as other types of substance abuse (Comings et al., 1999; Sander et al., 1995), and with schizophrenia (F. Zhang et al., 2011). 


\section{DRD4}

The dopamine receptor type 4 gene is a relatively short gene (about 3,400 base pairs), and much of the variability in this gene can be captured through one 48 base pair VNTR in exon 3. This VNTR can have between 2 and 11 repeats of this 48 base pair segment. Alleles are referred to by the number of repeat segments. Usually, the 7 allele is established as a risk allele for many different disorders, including ADHD and schizophrenia. The 7 allele has also been associated with greater novelty seeking behavior (Noble et al., 1998), although later studies have questioned those results (Schinka, Letsch, \& Crawford, 2002). In preschool children, carriers of the 7 allele consumed more fat and protein than did those possessing different repeat lengths (Silveira et al., 2013), suggesting that the type of food preferred could be dependent on dopaminergic genotype.

In vitro, the 7 repeat has been shown to bind less tightly to dopamine due to alterations in the activity of cAMP (Asghari et al., 1995). The 7 repeat allele is the variant that reduces cAMP levels the most, but another allele, the 2 allele, is nearly as effective at this reduction (Asghari et al., 1995). It has been suggested that due to evolutionary and biochemical similarities, the 2 and 7 repeat alleles should be grouped together as risk alleles (Reist et al., 2007). Reist and co-authors found a significant difference in novelty seeking behavior when the alleles were grouped this way, instead of the more common short versus long allele comparison (Reist et al., 2007).

\section{Dopamine Transporter Gene}

Neurotransmitter transporters are portals built into the cell membranes of neurons. They function to remove neurotransmitters from the synapse after they are no longer needed. In the case of dopamine, there is only one transporter, the dopamine active transporter, SLC6A3. This same gene is also called DAT1.

In the 3' untranslated region of the SLC6A3/DAT1, there is a variable number tandem repeat (VNTR) that greatly affects dopamine clearance from the synapse. It has been suggested that this VNTR alters translation of the mRNA into protein (Heinz et al., 2000). However, evidence regarding the implications of each variant is somewhat mixed. It has been shown that the 9 repeat allele causes the transcription of SLC6A3/DAT1 to be increased, resulting in more transporters. As a result, more dopamine undergoes reuptake by the presynaptic neurons, and there is less dopamine available to bind to postsynaptic neurons (Blum, Chen, et al., 2011). However, it has also been shown that subjects with the 9 repeat allele have lower numbers of dopamine transporters as compared to those with the 10 repeat allele (Heinz et al., 2000). 


\section{Dopamine Degradation Genes}

Other important dopaminergic genes associated with reward include catechol-omethyltransferase (COMT) and monoamine oxidase isomers A and B (MAOA and MAOB). These enzymes break down dopamine, and along with reuptake of the neurotransmitter, reduce the amount of dopamine available in the synaptic cleft. When these degradation mechanisms are altered, the levels of available dopamine could either increase or decrease.

\section{COMT}

Catechol-o-methyltransferase (COMT) is associated with reward through its influence on dopamine availability in the cortex. It is the only enzyme that can act to methylate synaptic dopamine and begin the breakdown process. The met allele of a common polymorphic site (Val108/158Met, rs4680) causes this enzyme to have lower activity (Caldu et al., 2007). Individuals with the met allele report decreased numbers of rewarding experiences in daily life (Wichers et al., 2008). As a result, these individuals seek out the reward "high". This polymorphism has been suggested as a marker, and potential drug target, for addiction (Blum \& Gold, 2011; Tunbridge et al., 2012). In addition, the rs4680 met allele is associated with increased abdominal obesity in men (Annerbrink et al., 2008). However, Galvao found an increase in consumption of high fat and high sugar food for those with the val allele (Galvao et al., 2012).

Approximately 64 kilobases away from rs4680 is a synonymous $\mathrm{G} / \mathrm{C}$ variant rs4818 (Leu136Leu). Although there is no functional change in the protein produced from this gene, the $\mathrm{C}$ allele of this polymorphism has been associated with increased BMI (S. S. Wang et al., 2007). It appears likely that this polymorphism acts as a marker in linkage disequilibrium with another causal variant, perhaps rs4818 noted above.

\section{MAOA}

Monoamine oxidase $\mathrm{A}$ is an enzyme that deaminates dopamine, changing the overall bioavailability of the neurotransmitter. It, and its partner MAOB, are located in the mitochondria of neurons and break down dopamine that has already been removed from the synaptic cleft. A 30 base pair variable number tandem repeat (VNTR) polymorphism of the MAOA isoform of this gene is known to be in the promoter region (Camarena et al., 2004; Need et al., 2006). The promoter region of a gene is where the initial binding of transcription proteins takes place, and so polymorphisms in this area are particularly influential on gene product availability. In the case of this VNTR polymorphism, repeat alleles from 2 to 5 have been recorded. The most common alleles are the 3,3.5, and 4 repeat alleles, although there is variation in the frequencies within certain racial and ethnic groups (Sabol, Hu, \& Hamer, 1998). Individuals with the 3.5 and 4 repeat alleles show greater mRNA production than those with the other alleles (Sabol et al., 1998), and it has been shown that boys with the longer repeats have a greater 
preference for high fat and sugary foods than those with shorter repeats (Galvao et al., 2012). Additionally, shorter alleles have been shown to be in transmission disquilibrium in obese families (Camarena et al., 2004).

\section{МАОB}

The A allele of a SNP in the MAOB isoform of this gene (B-SNP13, rs1799836) correlates with higher dopamine levels in the brain (Balciuniene, Emilsson, Oreland, Pettersson, \& Jazin, 2002). Although it is important to note that MAOA and MAOB have different distributions in tissues, they basically have identical activity for dopamine degredation. Reduced activity in only one isoform could potentially be compensated by increased activity in the other (Need et al., 2006). Both enzymes' activity must be taken into account. However, adipose tissue taken from obese subjects has been shown to have lower expression levels for both types of monoamine oxidases (Visentin et al., 2004), so a "double-hit" in both could potentially have large effects on weight. A significantly higher number of low activity genotypes was found in obese subjects, although the MAOB low activity polymorphism was not significantly associated with weight or BMI on its own (Need et al., 2006).

\section{Summary}

In summary, there is strong experimental evidence for the association between genes related to dopamine and changes in weight. This evidence supports the association at multiple different locations in dopamine production pathways, and suggests that changes in weight could be genetically driven at any of these different points. Any further work in obesity research should take into account this relationship. 


\section{CHAPTER 3. METHODOLOGY}

\section{Introduction}

This chapter presents the methodology used to address the study aims: 1) To evaluate the ability of polymorphisms in a subset of dopaminergic genes to predict weight gain in kidney transplant recipients and 2) To determine the interaction of those polymorphisms with demographic characteristics (age, race, and gender) and their combined ability to predict weight gain in a kidney transplant population. First, the design, sample, and setting are described. The remainder of the chapter describes the demographic and genetic sample handling, the process of gene selection, the laboratory analyses, and statistical analyses.

\section{Design}

A candidate gene association approach was used to study weight gain in a subset of kidney transplant recipients with repository samples obtained from participants in a larger prospective study. This approach was used to determine the influence of selected dopaminergic polymorphisms on weight gain in kidney transplant recipients.

\section{Sample}

This study employed a subsample of 70 subjects from a larger observational study that examined genetic and lifestyle predictors of obesity following kidney transplantation. All subjects from the original parent study who had pre and post-transplant weight measures and repository buffy coat samples were included in this study. Additionally, race, gender, and date of birth were obtained from the original parent study. Inclusion and exclusion criteria for the original parent study are shown in Table 3-1. Note that none of these criteria were for phenotypes that are known to be impacted by dopamine.

\section{Setting}

This study was conducted at Methodist University Transplant Institute in Memphis, Tennessee. This center has been in partnership with the University of Tennessee Health Science Center since 2004 and serves the greater midsouth area, including Mississippi, Arkansas, and West Tennessee. The center is unique because the population of the city of Memphis is $63.3 \%$ African American, which lends increased racial diversity for this study (Bureau, 2011). Subjects were voluntarily recruited from all patients at this center awaiting kidney transplantation and meeting inclusion/exclusion criteria from August of 2007 until March of 2011. 
Table 3-1. Inclusion and exclusion criteria.

\begin{tabular}{ll}
\hline Inclusion criteria & Exclusion criteria \\
\hline Males or females between 18-70 years & $\begin{array}{l}\text { Multiple organ transplantation } \\
\text { Peceiving first transplantation }\end{array}$ \\
$\begin{array}{l}\text { Ability to read and write in English } \\
\text { White blood cells collected at time of }\end{array}$ & \\
transplantation & \\
Baseline and 12 month weight and height \\
Race, gender, date of birth information is \\
available
\end{tabular}




\section{Methods}

\section{Demographic Information}

Demographic information was originally obtained during the parent study, and was reported in a deidentified format for this substudy. Race, gender, and date of birth were self-reported. Age was calculated from the date of birth to the date of transplantation and measured in years and fractional months. Baseline weight at time of transplantation was obtained from surgical records. Height and 12-month weight were obtained from the transplant clinic chart and used to determine weight change and BMI. Based upon this BMI, patients were assigned a weight classification according to the National Institutes for Health guidelines for BMI as shown in Table 3-2 with borderline cases rounded to the nearest tenth.

\section{Genetic Sample}

As a part of the original parent study, whole blood was obtained immediately prior to the transplant surgery. At that time, the blood was centrifuged to separate plasma, the buffy coat containing the white blood cells and platelets, and erythrocytes. The buffy coat was stored in a separate tube and kept frozen in a - 80 degree Celsius freezer for 3 to 5 years. Then, at the time of this study, the frozen buffy coat samples were shipped on dry ice to the University of Pittsburgh, where DNA was extracted from the white blood cells using the Qiagen Flexigene DNA kit.

\section{Gene Selection}

The dopaminergic genes hypothesized to be related to weight gain in kidney transplant recipients were selected through a three-fold method. This method included selecting all the dopaminergic candidate genes significant in previous data, then refining this list through the use of bioinformatics tools that allowed the selection of variants, and finally conducting a traditional literature review to further refine the list of variants.

Preliminary gene selection came from the results of a gene expression study conducted in the parent study (Cashion et al., 2013). In brief, this study conducted microarray analyses on subcutaneous adipose tissue taken from 26 kidney transplant recipients at the time of surgery. Relative weight change of the subjects at 6 months after transplantation was regressed on the gene expression levels at baseline while controlling for gender and race. A total of 1553 genes (or 1936 probes) were found to be significantly associated with weight change. Using the systems biology based bioinformatics tools Gene Ontology and the Kyoto Encyclopedia of Genes and Genomics, several of these genes were found be in dopaminergic pathways (Table 3-3). 
Table 3-2. NIH weight classification guidelines.

\begin{tabular}{ll}
\hline BMI & Weight category \\
\hline$<18.5 \mathrm{~kg} / \mathrm{m}^{2}$ & Underweight \\
$18.5-24.9 \mathrm{~kg} / \mathrm{m}^{2}$ & Normal weight \\
$>25<30 \mathrm{~kg} / \mathrm{m}^{2}$ & Overweight \\
$>30 \mathrm{~kg} / \mathrm{m}^{2}$ & Obese \\
\hline
\end{tabular}

Table 3-3. Results from adipose tissue microarray study.

\begin{tabular}{lllc}
\hline Bioinformatics tool & Category & $\begin{array}{l}\text { Number of } \\
\text { genes }\end{array}$ & $\boldsymbol{p}$ Value \\
\hline Gene Ontology & $\begin{array}{l}\text { Regulation of dopamine secretion } \\
\text { genes }\end{array}$ & 5 & 0.0004 \\
Gene Ontology & $\begin{array}{l}\text { G protein coupled receptor protein } \\
\text { signaling activity }\end{array}$ & 11 & 0.0019 \\
$\begin{array}{l}\text { Gene Ontology } \\
\begin{array}{l}\text { Kyoto Encyclopedia } \\
\text { of Genes and }\end{array}\end{array}$ & $\begin{array}{l}\text { Parkinson's disease } \\
\text { Genomes }\end{array}$ & 12 & 0.0086 \\
\hline
\end{tabular}


The 47 candidate dopaminergic pathway genes found in the preliminary stage of gene selection became the first pass list of genes to be tested in the current study. Then, the software program Ingenuity pathway analysis (IPA, Ingenuity Systems) was used to select those dopaminergic genes most significantly $(\mathrm{p} \leq 0.05)$ associated with weight gain at 6 months post-transplantation (Figure 3-1). The IPA diagram has separated the genes to show the location of gene product activity in relationship to the neuronal cell body.

To further refine this list, a traditional review of literature was conducted to determine which of these dopaminergic genes were most highly associated with obesity. Review was limited to articles published between 2003-2013, written in English, and entered into a PubMed, CINAHL, or Google Scholar database. The genes DRD2, DRD3, DRD4, COMT, MAOA, MAOB, and SLC6A3 (also known as DAT1) were found to be those most highly associated with obesity in the literature.

For the final step of gene selection, it was hypothesized that the remaining seven genes might have polymorphisms that cause a differential expression in adipose tissue related to weight gain. To assist in testing this hypothesis, GeneIndexer software was used to link keywords (dopamine, obesity, kidney transplant, addiction, weight gain) to polymorphisms reported in the PubMed literature. These genes were then investigated using dbSNP to search for noncoding SNPs that could explain the differential expression seen in kidney transplant recipients. The final list of polymorphisms discovered by these methods is shown in Table 3-4.

It was also noted that there were other types of polymorphisms, such as VNTRs, that when coupled with the SNPs, could capture an even greater portion of the variance in these genes. Therefore, the VNTRs for DRD4, SLC6A3/DAT1, and MAOA were selected for their relationship to weight gain. See Table 3-5 for more information on these variants and their alleles. While all variants have different minor allele frequencies depending upon racial and ethnic backgrounds, this information is particularly important for VNTRs. Since the sample for this study was predominantly of Caucasian and African American descent, the allele frequencies for just these two racial groups is presented in Table 3-5. Allele frequencies from this study sample have also been listed for reference.

In the current study, variants meeting threshold criteria $(\mathrm{p} \leq 0.2)$ were incorporated into a stepwise regression modelling. These variants were also regressed with demographic characteristics (age, race, and gender) to determine their combined predictive value in post-transplant weight gain.

\section{Genotype Data Collection}

Buffy coat samples were extracted using the Qiagen Flexigene DNA kit. SNP genotyping was performed using commercially available TaqMan ${ }^{\circledR}$ assay kits specific 


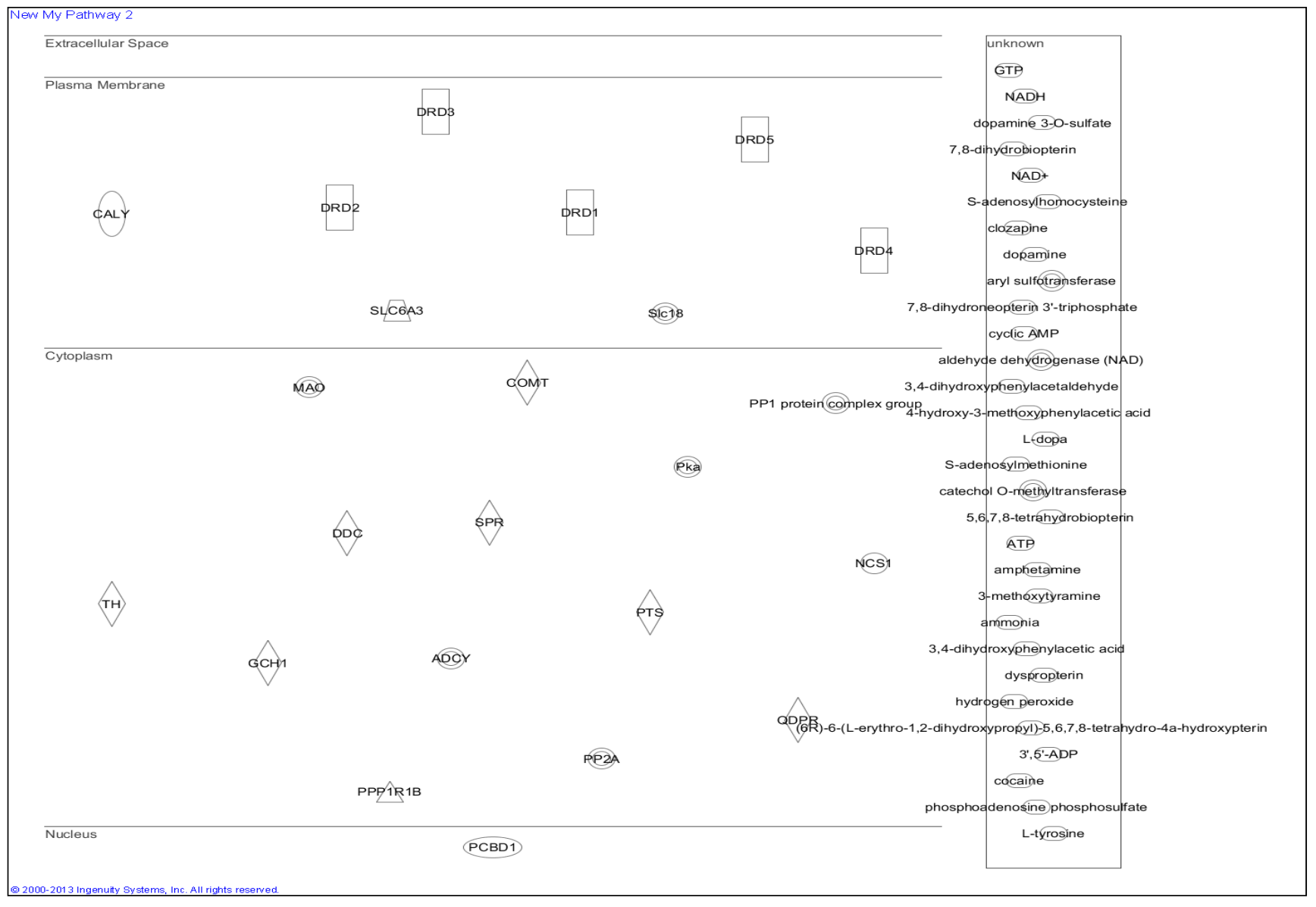

Figure 3-1. IPA diagram showing dopaminergic pathway gene expression changes.

Note: Original figure created by the author using Ingenuity systems software, (C) 2000-2013 Ingenuity Systems, Inc. All rights reserved. 
Table 3-4. Dopaminergic single nucleotide polymorphisms.

\begin{tabular}{|c|c|c|c|c|c|}
\hline Gene & Variant & $\begin{array}{l}\text { Alternative } \\
\text { name }\end{array}$ & Type & $\begin{array}{l}\text { Minor allele } \\
\text { frequency }\end{array}$ & $\begin{array}{l}\text { Type of } \\
\text { variant }\end{array}$ \\
\hline DRD2 & rs 1800497 & Taq1A & Receptor & $\mathrm{T}=0.296$ (vs. C) & missense \\
\hline DRD2 & rs6277 & $\mathrm{C} 957 \mathrm{~T}$ & Receptor & $\mathrm{A}=0.273$ (vs. $\mathrm{G})$ & intragenic \\
\hline DRD2 & rs12364283 & NA & Receptor & $\mathrm{G}=0.037$ (vs. A) & intragenic \\
\hline DRD3 & rs6280 & Ser9Gly & Receptor & $\mathrm{C}=0.452($ vs. T) & missense \\
\hline COMT & rs 4680 & $\begin{array}{l}\text { Val108/158 } \\
\text { Met }\end{array}$ & $\begin{array}{l}\text { Dopamine } \\
\text { availability }\end{array}$ & $A=0.391$ (vs. $G)$ & missense \\
\hline COMT & rs 4818 & Leu136Leu & $\begin{array}{l}\text { Dopamine } \\
\text { availability }\end{array}$ & $\mathrm{G}=0.31$ (vs. C) & intragenic \\
\hline MAOB & rs1799836 & B-SNP13 & $\begin{array}{l}\text { Dopamine } \\
\text { availability }\end{array}$ & $\mathrm{C}=0.431($ vs. $\mathrm{T})$ & intragenic \\
\hline
\end{tabular}


Table 3-5. Dopaminergic variable number tandem repeats.

\begin{tabular}{|c|c|c|c|c|c|c|c|c|}
\hline Gene & Variant & Type & $\begin{array}{l}\text { Repeat } \\
\text { size }\end{array}$ & $\begin{array}{l}\text { Location of } \\
\text { repeat }\end{array}$ & Allele & $\begin{array}{l}\text { Frequency } \\
\text { (Caucasian } \\
\text { descent) }\end{array}$ & $\begin{array}{l}\text { Frequency } \\
\text { (African } \\
\text { descent) }\end{array}$ & $\begin{array}{l}\text { Frequency } \\
\text { (study } \\
\text { population) }\end{array}$ \\
\hline \multirow[t]{9}{*}{ DRD4 } & VNTR & Receptor & $48 \mathrm{bp}$ & Exon 3 & 2 & 0 & 0 & 0.054 \\
\hline & & & & & 3 & 0.068 & 0 & 0.046 \\
\hline & & & & & 4 & 0.080 & 0.747 & 0.877 \\
\hline & & & & & 5 & 0.648 & 0.011 & 0.023 \\
\hline & & & & & 6 & 0.017 & 0.011 & 0 \\
\hline & & & & & 7 & 0.006 & 0.207 & 0 \\
\hline & & & & & 8 & 0.176 & 0.006 & 0 \\
\hline & & & & & 9 & 0.006 & 0 & 0 \\
\hline & & & & & 10 & 0 & 0.017 & 0 \\
\hline \multirow{9}{*}{$\begin{array}{l}\text { SLC6A3 } \\
\text { /DAT1 }\end{array}$} & VNTR & Dopamine & $40 \mathrm{bp}$ & 3' UTR & 3 & 0 & 0.010 & 0 \\
\hline & & & & & 6 & 0 & 0 & 0 \\
\hline & & & & & 7 & 0.010 & 0.030 & 0 \\
\hline & & & & & 8 & 0.003 & 0.044 & 0 \\
\hline & & & & & 9 & 0.228 & 0.174 & 0.147 \\
\hline & & & & & 10 & 0.755 & 0.725 & 0.816 \\
\hline & & & & & 11 & 0 & 0.010 & 0.022 \\
\hline & & & & & 12 & 0 & 0 & 0 \\
\hline & & & & & 13 & 0.003 & 0 & 0 \\
\hline \multirow[t]{4}{*}{ MAOA } & VNTR & $\begin{array}{l}\text { Dopamine } \\
\text { availability }\end{array}$ & $30 \mathrm{bp}$ & $\begin{array}{l}\text { Promoter } \\
\text { region }\end{array}$ & 2 & unknown & unknown & 0.037 \\
\hline & & & & & 3 & unknown & unknown & 0.449 \\
\hline & & & & & 3.5 and 4 & $0.65^{*}$ & $0.39 *$ & 0.485 \\
\hline & & & & & 5 & unknown & unknown & 0.029 \\
\hline
\end{tabular}

*Sabol, S. Z., Hu, S., \& Hamer, D. (1998). A functional polymorphism in the monoamine oxidase A gene promoter. Human Genetics, 103(3), 273-279. 
for each polymorphism. All TaqMan® assays were conducted on the ABI Prism 7000

Sequence Detection System. VNTRs were genotyped using RFLP and gel electrophoresis (Appendix A). For quality control, all genotypes were determined by two individuals, both blinded to phenotype. An example output for the TaqMan ${ }^{\circledR}$ assay is shown in Figure 3-2. A portion of a RFLP electrophoresis gel is shown in Figure 3-3. Genotypes may be read from top to bottom in the following way, such that lane 1 has a $2 / 4$ genotype. Lane 2 has a $4 / 4$ genotype. Lane 3 has a 2/4 known and sequenced control genotype. Lanes 4 and 5 represent known and sequenced $3 / 4$ control genotypes.

\section{Statistical Analyses}

Variables used in study analyses are presented in Table 3-6.

\section{Statistical Analysis-Sample Description}

The sample was characterized by age in years at time of transplantation, selfreported race, gender, and weight at baseline and 12 months. Height data allowed the calculation of BMI, as well as changes in BMI at one year post transplantation. Weight change at 12 months was calculated as both raw change in kilograms, and also as a percentage of total pretransplant body weight.

Descriptive data were calculated in Excel 2010 and presented as means, standard deviations, and ranges. The same data were also examined with appropriate correlations, $t$ tests, chi squares, and ANOVA statistical tests.

\section{Statistical Analysis-Aim 1}

To evaluate the ability of dopaminergic polymorphisms to predict weight gain in kidney transplant recipients, each variant was analyzed using ANOVA, chi squares, and point biserial correlations as appropriate. All analyses were conducted initially using a dose dependent approach (i.e. that a genotype AA is different from Aa, and each of those genotypes is different from aa) and subsequently in a risk allele fashion (i.e. that those individuals either homozygous or heterozygous for the risk allele are compared to those not carrying a risk allele). This approach was used for the outcome measure of raw weight change in kilograms, and also with the outcome measure of total percent weight change. Genetic variants identified as approaching significance (using the standard $\mathrm{p}<0.20$ ) were characterized as having the potential to predict weight gain, and were included in subsequent regression modelling for aim 2 (Bursac, Gauss, Williams, \& Hosmer, 2008). 


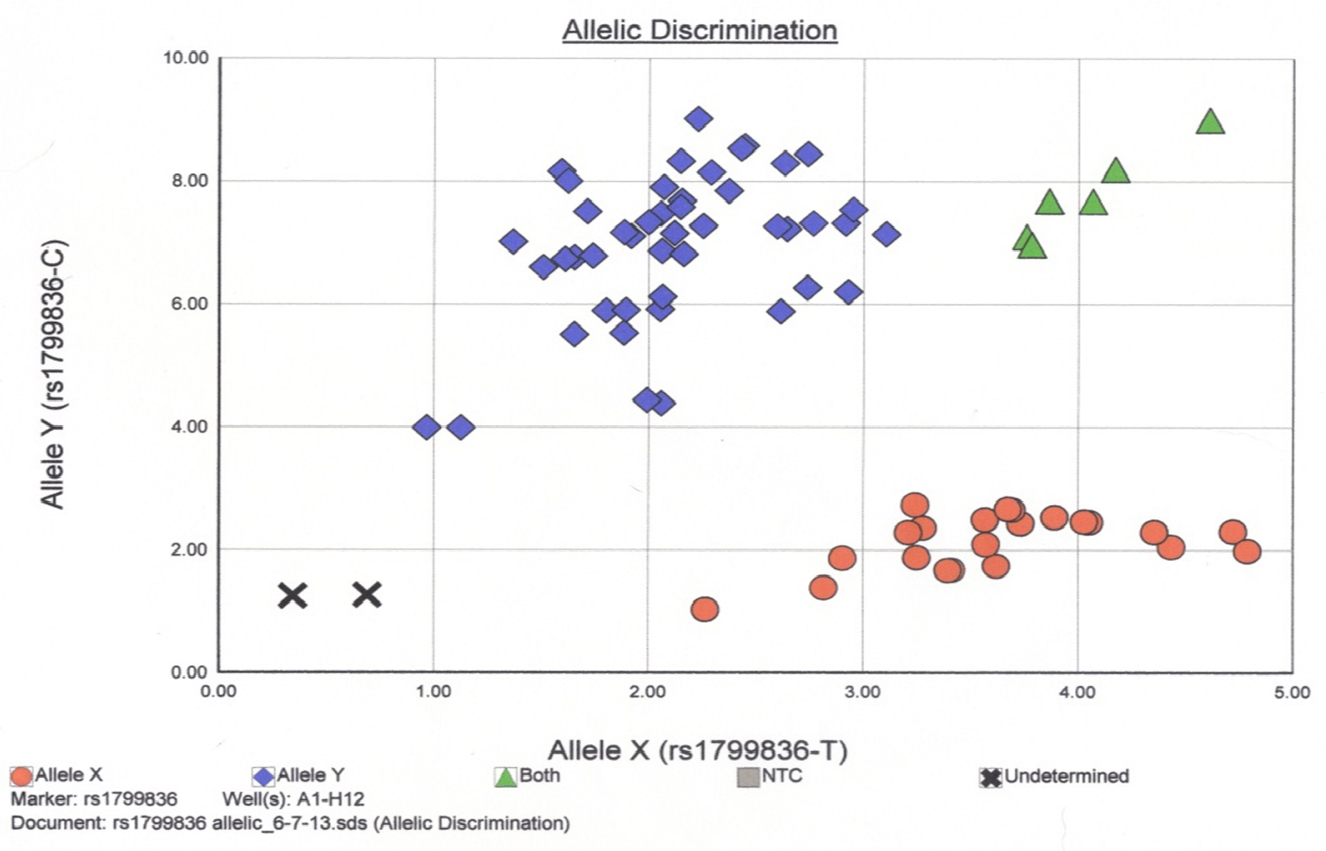

Figure 3-2. Genotype output for rs1799836.

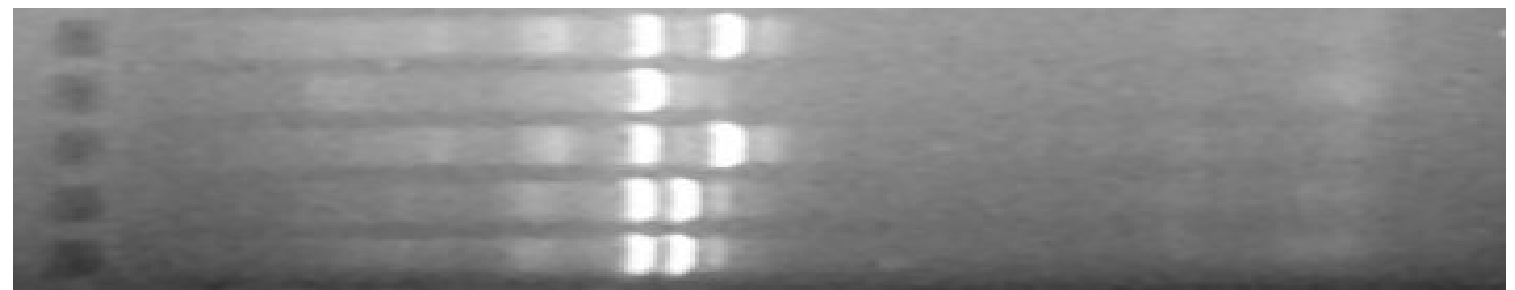

Figure 3-3. Selected lanes of DRD4 VNTR agarose gel used for genotyping. 
Table 3-6. Variables for analysis.

\begin{tabular}{|c|c|c|}
\hline Variables & Measurements & Operational \\
\hline Polymorphisms & Dopaminergic genetic profile & $\begin{array}{l}\text { Allelic discrimination to } \\
\text { generate genotype }\end{array}$ \\
\hline $\begin{array}{l}\text { Demographic factors: } \\
\text { Age }\end{array}$ & $\begin{array}{l}\text { Self reported DOB from clinic } \\
\text { records }\end{array}$ & $\begin{array}{l}\text { Age in years at time of } \\
\text { transplantion }\end{array}$ \\
\hline $\begin{array}{l}\text { Demographic factors: } \\
\text { Race }\end{array}$ & $\begin{array}{l}\text { Self reported race from clinic } \\
\text { records }\end{array}$ & $\begin{array}{l}\text { Categorized as AA, } \\
\text { white, hispanic, other }\end{array}$ \\
\hline $\begin{array}{l}\text { Demographic factors: } \\
\text { Gender }\end{array}$ & $\begin{array}{l}\text { Self reported gender from clinic } \\
\text { records }\end{array}$ & Male or female \\
\hline Height & $\begin{array}{l}\text { Surgical records from time of } \\
\text { transplantation }\end{array}$ & Height in meters \\
\hline Pretransplant weight & $\begin{array}{l}\text { Surgical records from time of } \\
\text { transplantation }\end{array}$ & Weight in kilograms \\
\hline $\begin{array}{l}12 \text { month post- } \\
\text { transplant weight }\end{array}$ & $\begin{array}{l}\text { Transplant clinic records at } 12 \\
\text { months post-transplant }\end{array}$ & Weight in kilograms \\
\hline $\begin{array}{l}\text { Weight change at } 12 \\
\text { months }\end{array}$ & $\begin{array}{l}\text { (12 month post-transplant weight } \\
\text { - pretransplant weight)/ } \\
\text { Pretransplant weight }\end{array}$ & $\begin{array}{l}\text { Percentage of total } \\
\text { pretransplant body } \\
\text { weight }\end{array}$ \\
\hline
\end{tabular}




\section{Statistical Analysis-Aim 2}

For aim 2, the variants meeting criteria $(p \leq 0.20)$ from the statistical analysis of aim 1 were combined with demographic characteristics (age, race, and gender). All demographic statistics were calculated using Microsoft Excel 2010. Descriptive data are presented as means, standard deviations, and ranges; and were examined with appropriate correlations, $t$ tests, chi squares, and ANOVA statistical tests. A simple linear regression model was built with demographic variants meeting criteria $(p \leq 0.20)$ from initial statistical testing.

The multiple regression model was built in a step wise fashion, first starting with all demographic factors only, then with each variant meeting criteria $(p \leq 0.20)$ from aim 1 added individually. No variables were removed from the model. A regression model was also calculated only using genetic factors and without any demographic characteristics, and then another with all demographic factors, and all genetic variants. As an exploratory exercise, a final regression model was calculated using only those factors that had $p \leq 0.20$ in other regression models. This analysis was calculated using Microsoft Excel 2010, and confirmed using the R statistical software package, version 2.14.1 (R Core Team, 2013).

The regression models were also tested with outliers more than \pm 2 standard deviations from the mean removed. No subjects were more than \pm 3 standard deviations from the mean, so the more stringent criteria of \pm 2 standard deviations from the mean was used as a cut point.

This study is intended as a pilot study to test the methodology and feasibility of this type of analysis, and so power, odds ratio (i.e. the ratio of gaining weight, given the possession of one or more copies of a risk allele), risk ratio, and effect sizes were all calculated post hoc.

\section{Summary}

This chapter presented the study design, sample and setting, methods undertaken to obtain data, and the analytical methods employed to address study aims. The next chapter will present in a manuscript format the results and conclusions of applying this methodology. 


\section{CHAPTER 4. DEMOGRAPHIC AND DOPAMINERGIC GENETIC CONTRIBUTIONS TO OBESITY IN KIDNEY TRANSPLANT RECIPIENTS}

\section{Introduction}

Approximately one third of all kidney transplant recipients will gain a significant amount of weight (6-13 kilograms) during the first year after transplantation (Cashion et al., 2007; Patel, 1998). This excessive weight gain negatively affects cardiovascular health and contributes to an increased incidence of diabetes (Kasiske, Snyder, Gilbertson, $\&$ Matas, 2003). Causes traditionally proposed for the weight gain following kidney transplantation include an improved appetite due to the resolution of uremia and side effects of standard anti-rejection medications (Cupples et al., 2012; Moore \& Gaber, 1996). However, research has shown steroid based immunosuppressive protocols do not have a clinically significant effect on weight gain (Akarsu et al., 2013; Cupples et al., 2012; van den Ham et al., 2003; Woodle et al., 2008). Additionally, studies conducted by the authors have found little difference in physical activity and nutritional intake among kidney transplant recipients who do and do not gain weight (Cupples et al., 2012). A small amount of the variance in weight gain can be explained by certain demographic characteristics (age, race, and gender), with older African American women being the most likely to gain weight (Cashion et al., 2007). However, these demographic factors alone cannot predict who will and who will not gain weight. The failure to find lifestyle or treatment related factors associated with post-transplant weight gain suggests that genetic factors may have a role in the differential weight gain experienced by kidney transplant recipients.

Dopamine is a neurotransmitter that has previously been implicated in substance addiction (Spreckelmeyer et al., 2011; G. J. Wang et al., 2011). Neurogenetic data have shown that dopamine may also play a role in models of food addiction behaviors, as dopamine receptor genes and genes related to overall dopamine activity have been associated with obesity, weight gain, and food addiction (Kenny, 2011; Volkow et al., 2011). Gene expression studies conducted by the authors in a subset of these kidney transplant recipients confirms that expression of some dopaminergic pathway genes in adipose tissue negatively correlate with weight gain (Cashion et al., 2013). Some of these differentially expressed genes have polymorphisms that may cause gene activity to be altered and place these individuals at a greater risk for gaining weight. Identification of individuals as being at a genetically or demographically higher risk for weight gain would enable implementation of personalized lifestyle interventions aimed at reducing environmental contributions to weight gain. The purpose of this study was to determine if polymorphisms associated with these previously identified dopaminergic genes have predictive value when combined with demographic characteristics for weight gain in the kidney transplant population. 


\section{Methods}

\section{Study Design}

A candidate gene association approach was used to study weight gain in a subset of kidney transplant recipients with repository samples obtained from participants in a larger prospective study. This design was used to address the following research aims: 1) To evaluate the ability of dopaminergic polymorphisms to predict weight gain in kidney transplant recipients, and 2) To determine the interaction of polymorphisms predictive of weight gain with demographic characteristics (age, race, and gender) and their combined ability to predict weight gain in a kidney transplant population.

\section{Setting}

This study was conducted at Methodist University Transplant Institute in Memphis, Tennessee. This center has been in partnership with the University of Tennessee Health Science Center since 2004 and serves the greater midsouth area, including Mississippi, Arkansas, and West Tennessee. The center is unique because the population of the city of Memphis is $63.3 \%$ African American, which lends increased racial diversity for this study (Bureau, 2011). Subjects were voluntarily recruited from all patients at this center awaiting kidney transplantation and meeting inclusion/exclusion criteria from August of 2007 until March of 2011.

\section{Sample}

This study encompassed a subsample of a larger observational study on demographic and genetic factors related to weight gain after kidney transplantation. To meet criteria for this subsample, the patient had to sign a repository consent form to allow their genetic data to be used in future work. For Institutional Review Board approval, please see Appendix B. As a part of the larger study, age, race, and gender information was collected, as well as baseline weight and height and 12 month post-transplant weight. These variables were shared in a deidentified format. Blood was taken at the time of kidney transplant surgery and buffy coat samples were frozen and stored in a $-80^{\circ} \mathrm{C}$ freezer. Time from collection to storage was between 3 and 5 years for each sample.

\section{Laboratory Analyses}

Buffy coat samples were extracted using the Qiagen Flexigene DNA kit. For SNPs, genotyping was performed using commercially available TaqMan ${ }^{\circledR}$ assay kits specific for each polymorphism. All TaqMan ${ }^{\circledR}$ assays were conducted on the ABI Prism 7000 Sequence Detection System. VNTRs were genotyped using RFLP and gel electrophoresis (Table 4-1). For quality control, all genotypes were determined by two individuals, both blinded to phenotype. 
Table 4-1. Laboratory methods for dopaminergic SNPs and VNTRs.

\begin{tabular}{|c|c|c|c|}
\hline Variant & Method & $\begin{array}{l}\text { Concentrations of reagents } \\
\text { for master mix (per sample) }\end{array}$ & $\begin{array}{l}\text { Thermal cycler } \\
\text { conditions }\end{array}$ \\
\hline $\begin{array}{l}\text { rs4680, rs4818, } \\
\text { rs6277, rs6280, } \\
\text { rs12364283, } \\
\text { rs1800497 }\end{array}$ & Taqman $^{\circledR}$ & $\begin{array}{l}\text { (total of } 28 \mu \mathrm{L} \text { ) } \\
\text { - } \quad \text { Water } 5.5 \mu \mathrm{L} \\
\text { - } \quad \text { PCR mix } 6.25 \mu \mathrm{L} \\
\text { - } \quad \text { 40x assay } 0.3125 \mu \mathrm{L} \\
\text { - } \quad \text { DNA } 1.1 \mu \mathrm{L}\end{array}$ & $\begin{array}{l}\text { 1. } 95^{\circ} \mathrm{C} \text { for } 10 \\
\text { minutes. } \\
\text { 2. } 95^{\circ} \mathrm{C} \text { for } 15 \\
\text { seconds. } \\
\text { 3. } 60^{\circ} \mathrm{C} \text { for } 1 \text { minute. } \\
\text { 4. Repeat step } \# 2 \mathrm{x} \\
\text { 40. }\end{array}$ \\
\hline rs1799836 & $\operatorname{Taqman}^{\circledR}$ & 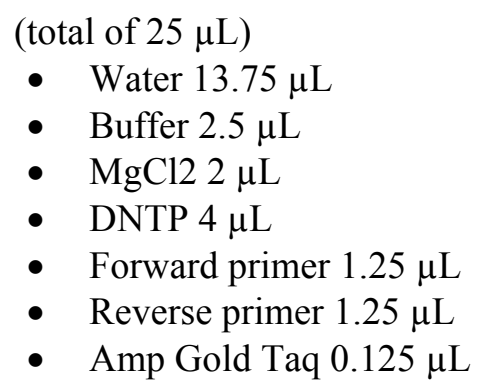 & $\begin{array}{l}\text { 1. } 95^{\circ} \mathrm{C} \text { for } 10 \\
\text { minutes. } \\
\text { 2. } 95^{\circ} \mathrm{C} \text { for } 1 \text { minute. } \\
\text { 3. } 54^{\circ} \mathrm{C} \text { for } 30 \\
\text { seconds. } \\
\text { 4. Repeat step } \# 2 \mathrm{x} \\
\text { 35. } \\
\text { 5. Held at } 10^{\circ} \mathrm{C} \text {. }\end{array}$ \\
\hline Taq1A & RFLP & $\begin{array}{ll}\text { (total of } 28 \mu \mathrm{L} \text { ) } \\
\text { - } & \text { Water } 13.75 \mu \mathrm{L} \\
\text { - } & \text { Buffer } 2.5 \mu \mathrm{L} \\
\text { - } & \mathrm{MgCl}_{2} 2 \mu \mathrm{L} \\
\text { - } & \text { DNTP } 4 \mu \mathrm{L} \\
\text { - } & \text { Forward primer } 1.25 \mu \mathrm{L} \\
\text { - } & \text { Reverse primer } 1.25 \mu \mathrm{L} \\
\text { - } & \text { Taq polymerase } 0.125 \\
& \mu \mathrm{L} \\
\text { - } & \text { DMSO } 3 \mu \mathrm{L}\end{array}$ & $\begin{array}{l}\text { 1. } 95^{\circ} \mathrm{C} \text { for } 10 \\
\text { minutes. } \\
\text { 2. } 95^{\circ} \mathrm{C} \text { for } 1 \text { minute. } \\
\text { 3. } 65^{\circ} \mathrm{C} \text { for } 30 \\
\text { seconds. } \\
\text { 4. } 72^{\circ} \mathrm{C} \text { for } 1 \text { minute. } \\
\text { 5. Repeat step } \# 2 \mathrm{x} \\
\text { 35. } \\
\text { 6. Held at } 10^{\circ} \mathrm{C} \text {. }\end{array}$ \\
\hline MAOA VNTR & RFLP & $\begin{array}{ll}\text { (26 } \mu \mathrm{L} \text { per sample) } \\
\text { - } \quad \text { Water } 13.3 \mu \mathrm{L} \\
\text { - } \quad \text { Buffer } 2.5 \mu \mathrm{L} \\
\text { - } \mathrm{MgCl}_{2} 0.8 \mu \mathrm{L} \\
\text { - } \quad \text { DNTPs } 4 \mu \mathrm{L} \\
\text { - } \quad \text { Forward primer } 1.25 \mu \mathrm{L} \\
\text { - } \quad \text { Reverse primer } 1.25 \mu \mathrm{L} \\
\text { - } \quad \text { Denville's Taq } \\
\quad \text { polymerase } 0.125 \mu \mathrm{L}\end{array}$ & $\begin{array}{l}\text { 1. } 95^{\circ} \mathrm{C} \text { for } 1 \text { minute. } \\
\text { 2. } 55^{\circ} \mathrm{C} \text { for } 30 \\
\text { seconds. } \\
\text { 3. } 72^{\circ} \mathrm{C} \text { for } 1 \text { minute. } \\
\text { 4. Repeat step } \# 1 \mathrm{x} \\
\text { 35. } \\
\text { 5. Held at } 10^{\circ} \mathrm{C} \text {. }\end{array}$ \\
\hline
\end{tabular}


Table 4-1. (continued).

\begin{tabular}{|c|c|c|c|}
\hline Variant & Method & $\begin{array}{l}\text { Concentrations of reagents } \\
\text { for master mix (per sample) }\end{array}$ & $\begin{array}{l}\text { Thermal cycler } \\
\text { conditions }\end{array}$ \\
\hline $\begin{array}{l}\text { SLC6A3/DAT1 } \\
\text { VNTR }\end{array}$ & RFLP & $\begin{array}{ll} & (26 \mu \mathrm{L} \text { per sample) } \\
\text { - } & \text { Water } 13.75 \mu \mathrm{L} \\
\text { - } & \text { Buffer/ } \mathrm{MgCl}_{2} 2.5 \mu \mathrm{L} \\
\text { - } & \text { DMSO } 3 \mu \mathrm{L} \\
\text { - } & \text { DNTPs } 4 \mu \mathrm{L} \\
\text { - } & \text { Forward primer } 1.25 \mu \mathrm{L} \\
\text { - } & \text { Reverse primer } 1.25 \mu \mathrm{L} \\
\text { - } & \text { Denville's Taq } \\
& \text { polymerase } 0.125 \mu \mathrm{L}\end{array}$ & $\begin{array}{l}\text { 1. } 95^{\circ} \mathrm{C} \text { for } 30 \\
\text { seconds. } \\
\text { 2. } 57^{\circ} \mathrm{C} \text { for } 36 \\
\text { seconds. } \\
\text { 3. } 72^{\circ} \mathrm{C} \text { for } 40 \\
\text { seconds. } \\
\text { 4. } \text { Repeat step } \# 1 \mathrm{x} \\
\text { 35. } \\
\text { 5. } 72^{\circ} \mathrm{C} \text { for } 10 \\
\text { minutes. }\end{array}$ \\
\hline DRD4 VNTR & RFLP & $\begin{array}{ll}\text { (25 } \mu \mathrm{L} \text { per sample) } \\
\text { - } \quad \text { Water } 13.75 \mu \mathrm{L} \\
\text { - } \quad \text { Buffer/ } \mathrm{MgCl}_{2} 2.5 \mu \mathrm{L} \\
\text { - } & \text { DMSO } 2 \mu \mathrm{L} \\
\text { - } & \text { DNTPs } 4 \mu \mathrm{L} \\
\text { - } & \text { Forward primer } 1.25 \mu \mathrm{L} \\
\text { - } & \text { Reverse primer } 1.25 \mu \mathrm{L} \\
\text { - } & \text { Denville's Taq } \\
& \text { polymerase } 0.125 \mu \mathrm{L}\end{array}$ & $\begin{array}{l}\text { 1. } 95^{\circ} \mathrm{C} \text { for } 30 \\
\text { seconds. } \\
\text { 2. } 70^{\circ} \mathrm{C} \text { for } 36 \\
\text { seconds. } \\
\text { 3. } 72^{\circ} \mathrm{C} \text { for } 40 \\
\text { seconds. } \\
\text { 4. } \\
\text { Repeat step } \# 1 \mathrm{x} \\
40 . \\
\text { 5. } 72^{\circ} \mathrm{C} \text { for } 5 \\
\text { minutes. }\end{array}$ \\
\hline
\end{tabular}


For the Taq1A RFLP, a check of the PCR products was run on a 1\% agarose gel at 200 volts for 1 hour and then the successful PCR products were digested with TaqaI, 10 units ENZ, and $2 \mu \mathrm{L}$ of $10 \mathrm{x}$ buffer. After digestion, the products were run on a $2 \%$ agarose gel at 200 volts for 1 hour, stained with ethidium bromide, and genotyped using a comparison to a genetic ladder and control samples of known sequenced genotype. For the remaining VNTRs, products were run on a $2 \%$ agarose gel at 200 volts for 1 hour and then stained with ethidium bromide. Subjects were genotyped using a comparison to a genetic ladder and control samples of known sequenced genotype

\section{Statistical Analysis-Sample Description}

The sample was characterized by age in years and fractional months at time of transplantation, self-reported race, self-reported gender, and weight at baseline and 12 months from clinical records. Height data allowed the calculation of BMI, as well as changes in BMI at one year post transplantation. Weight change at 12 months was calculated as both raw change in pounds, and also as a percentage of total pretransplant body weight.

Descriptive data were calculated in Excel 2010 and presented as means, standard deviations, and ranges. The same data were also examined with appropriate correlations, $\mathrm{t}$ tests, chi squares, and ANOVA statistical tests.

\section{Statistical Analysis-Aim 1}

To evaluate the ability of dopaminergic polymorphisms to predict weight gain in kidney transplant recipients, each variant was analyzed using ANOVA, chi squares, and point biserial correlations as appropriate. All analyses were conducted initially using a dose dependent approach (i.e. that a genotype AA is different from Aa, and each of those genotypes is different from aa) and subsequently in a risk allele fashion (i.e. that those individuals either homozygous or heterozygous for the risk allele are compared to those not carrying a risk allele). This approach was used for the outcome measure of raw weight change in pounds, and also with the outcome measure of total percent weight change. Genetic variants identified as approaching significance (using the standard $\mathrm{p}<0.20$ ) were characterized as having the potential to predict weight gain, and were included in subsequent regression modelling for aim 2 (Bursac et al., 2008).

\section{Statistical Analysis-Aim 2}

For aim 2 , the variants meeting criteria $(p \leq 0.20)$ from the statistical analysis of aim 1 were combined with demographic characteristics (age, race, and gender). All demographic statistics were calculated using Microsoft Excel 2010. Descriptive data are presented as means, standard deviations, and ranges; and were examined with appropriate correlations, t tests, chi squares, and ANOVA statistical tests. A simple linear regression 
model was built with demographic variants meeting criteria $(\mathrm{p} \leq 0.20)$ from initial statistical testing.

The multiple regression model was built in a step wise fashion, first starting with all demographic factors only, then with each variant meeting criteria $(p \leq 0.20)$ from aim 1 added individually. No variables were removed from the model. A regression model was also calculated only using genetic factors and without any demographic characteristics, and then another with all demographic factors, and all genetic variants. As an exploratory exercise, a final regression model was calculated using only those factors that had $p \leq 0.20$ in other regression models. This analysis was calculated using Microsoft Excel 2010, and confirmed using the R statistical software package, version 2.14.1 (R Core Team, 2013).

The regression models were also tested with outliers more than \pm 2 standard deviations from the mean removed. No subjects were more than \pm 3 standard deviations from the mean, so the more stringent criteria of \pm 2 standard deviations from the mean was used as a cut point.

This study is intended as a pilot study to test the methodology and feasibility of this type of analysis, and so power, odds ratio (i.e. the ratio of gaining weight, given the possession of one or more copies of a risk allele), risk ratio, and effect sizes were all calculated post hoc.

\section{Results}

\section{Sample Demographics}

This study included 70 subjects, of which $42.9 \%$ were female $(n=30)$. The sample was 57\% African American $(n=40)$, and 37\% Caucasian $(n=26)$, with 2 subjects identifying themselves as multiracial and 2 identifying as American Indian. Average age was $50.67 \pm 13.20$ years, baseline weight was $181.99 \pm 39.35$ pounds, and the average BMI was $28.28 \pm 4.76$ kilograms per meter squared. At twelve months, the average weight was $184.68 \pm 46.45$ pounds and the average BMI was $28.72 \pm 6.28$ kilograms per meter squared. The change in weight from the time of transplantation to 12 months ranged from a loss of 39.85 pounds to a gain of 55.67 pounds. A paired, two-tailed t-test found that neither mean weight for the group nor mean BMI changed from baseline to 12 months ( $p=0.29$ and 0.27 respectively). A comparison of the demographic characteristics in the substudy and the parent study is included in Table 4-2.

\section{Demographics and Weight Change}

A weak negative correlation between age and weight change in pounds was present at twelve months $(\mathrm{r}=-0.28, \mathrm{p}=0.018)$, and remained when the correlation was performed using percent weight change $(r=-0.32, \mathrm{p}=0.006$, percent weight change 
Table 4-2. A comparison of demographic characteristics from the substudy and parent study.

\begin{tabular}{|c|c|c|c|c|}
\hline Characteristic & Baseline substudy & 12 Months substudy & Baseline parent study & 12 Months parent study \\
\hline Female (n/\%) & $30 / 42.9$ & NA & $41 / 42.7$ & NA \\
\hline African American (n/\%) & $40 / 57$ & NA & $62 / 64.58$ & NA \\
\hline Age $($ mean \pm SD $)$ & $50.67 \pm 13.20$ & NA & $50.83 \pm 12.55$ & NA \\
\hline Weight in pounds (mean \pm SD) & $181.99 \pm 39.35$ & $184.68 \pm 46.45$ & $180.74 \pm 39.18$ & $186.30 \pm 46.63$ \\
\hline $\mathrm{BMI}($ mean $\pm \mathrm{SD})$ & $28.28 \pm 4.76$ & $28.72 \pm 6.28$ & $28.10 \pm 4.69$ & $29.32 \pm 6.22$ \\
\hline
\end{tabular}


$\left.=((12 \text { month weight-baseline weight }) / \text { baseline weight })^{*} 100\right)$. An unequal variances one tailed t-test found no difference in percent weight change or weight change in pounds by gender ( $\mathrm{p}=0.23$ and $\mathrm{p}=0.32$ respectively). Likewise, no differences were found for percent weight change or weight change in pounds for race $(p=0.77$ and $p=0.94$ respectively).

\section{Genotyping}

Genotyping failure rates ranged from $0-12.9 \%$ (Table 4-3). The larger failure rates can be partially attributed to a small number of subjects. Although these subjects were successfully genotyped on one or more of the variants tested, it is possible that there were differences in the concentrations of DNA that was extracted in the first part of this experiment. Additionally, since the sample is not in Hardy Weinberg equilibrium for every variant, genotyping failure rates may be higher for certain variants.

\section{Quality Control}

All genotyping was performed by two individuals blinded to phenotype, and a comparison of the two genotyping methods was also used. The rs1800497 SNP was genotyped using a commercially available TaqMan ${ }^{\circledR}$ assay and it was also genotyped using RFLP. A comparison of the genotype obtained by the 2 methods resulted in $80 \%$ concordance, with only $9 \%$ of individuals altering genotype. An additional 8 individuals were unable to be ascertained on one method. Both methods were included in the analyses, in order to capture any changes to results influenced by these subtle changes.

Calculations of Hardy Weinberg equilibrium for the SNPs are shown in Table 4-4 (Court, 2008). A small sample size did not allow relevant calculations for Hardy Weinberg equilibrium for the VNTRs tested in this study.

\section{Comparison of Genotype in Dose Dependent Manner}

The first analysis of genotype data was conducted in a dose dependent manner, which assumes that the homozygous dominant genotype is different from either the heterozygous or the homozygous recessive genotype. Thus, having the risk allele in either one or two doses makes a difference in the overall outcome. Two separate outcomes were considered; raw weight change in pounds and percent weight change (Table 4-5 and Table 4-6). In summary, using percent weight change for the outcome measurement resulted in several interesting findings. Of particular note are the findings for percent weight change associated with $\mathrm{rs} 1800497(\mathrm{r}=-0.28, \mathrm{p}=0.05)$, and the rs1799836 SNP $(\mathrm{r}=0.12, \mathrm{p}=0.16)$. Additionally, chi square analysis for the SLC6A3/DAT1 VNTR approached significance $(\mathrm{p}=0.18)$, as did the $\mathrm{rs} 1800497$ SNP ANOVA $(\mathrm{p}=0.18)$. 
Table 4-3. Genotyping failure rates.

\begin{tabular}{llll}
\hline Gene & Variant & Failure rate (n) & Percent failure rate \\
\hline DRD2 & rs1800497 & 4 & 5.7 \\
DRD2 & Taq1A & 4 & 5.7 \\
DRD2 & rs6277 & 9 & 12.9 \\
DRD2 & rs12364283 & 1 & 1.4 \\
DRD3 & rs6280 & 4 & 5.7 \\
DRD4 & VNTR & 5 & 7.1 \\
SLC6A3/DAT1 & VNTR & 2 & 2.9 \\
COMT & rs4680 & 4 & 5.7 \\
COMT & rs4818 & 4 & 5.7 \\
MAOA & VNTR & 2 & 2.9 \\
MAOB & rs1799836 & 0 & 0 \\
\hline
\end{tabular}

Table 4-4. Hardy Weinberg equilibrium.

\begin{tabular}{|c|c|c|c|c|c|c|}
\hline Gene & Variant & Genotype & Observed & Expected & $\mathbf{X}^{2}$ & $p$ Value \\
\hline \multirow{3}{*}{ DRD2 } & rs1800497 & $\mathrm{AA}$ & 6 & 6.7 & 0.15 & 0.70 \\
\hline & & $\mathrm{AG}$ & 30 & 28.6 & & \\
\hline & & GG & 30 & 30.7 & & \\
\hline \multirow[t]{3}{*}{ DRD2 } & Taq1A & $+/+$ & 33 & 32.8 & 0.02 & 0.89 \\
\hline & & +/- & 27 & 27.5 & & \\
\hline & & $-/-$ & 6 & 5.8 & & \\
\hline \multirow{3}{*}{ DRD2 } & rs6277 & GG & 33 & 36.2 & 5.41 & 0.02 \\
\hline & & $\mathrm{AG}$ & 28 & 21.6 & & \\
\hline & & AA & 0 & 3.2 & & \\
\hline \multirow[t]{3}{*}{ DRD2 } & rs 12364283 & AA & 62 & 60.3 & 11.36 & 0.0008 \\
\hline & & $\mathrm{AG}$ & 5 & 8.4 & & \\
\hline & & GG & 2 & 0.3 & & \\
\hline \multirow[t]{3}{*}{ DRD3 } & rs6280 & TT & 16 & 25.5 & 24.54 & 0.000001 \\
\hline & & $\mathrm{TC}$ & 50 & 31.1 & & \\
\hline & & $\mathrm{CC}$ & 0 & 9.5 & & \\
\hline \multirow[t]{3}{*}{ COMT } & rs4680 & AA & 11 & 8 & 2.62 & 0.11 \\
\hline & & $\mathrm{AG}$ & 24 & 30 & & \\
\hline & & GG & 31 & 28 & & \\
\hline \multirow[t]{3}{*}{ COMT } & rs 4818 & $\mathrm{CC}$ & 29 & 26.7 & 1.46 & 0.23 \\
\hline & & $\mathrm{GC}$ & 26 & 30.5 & & \\
\hline & & GG & 11 & 8.7 & & \\
\hline \multirow[t]{3}{*}{ MAOB } & rs1799836 & $\mathrm{CC}$ & 41 & 27.7 & 46.66 & 0.00001 \\
\hline & & CT & 6 & 32.7 & & \\
\hline & & TT & 23 & 9.7 & & \\
\hline
\end{tabular}


Table 4-5. Dose dependent comparison of genotype raw weight change in pounds.

\begin{tabular}{|c|c|c|c|c|c|c|}
\hline \multirow[b]{2}{*}{ Gene } & \multirow[b]{2}{*}{ Variant } & \multirow[b]{2}{*}{$\begin{array}{l}\text { Risk } \\
\text { allele }\end{array}$} & \multirow[b]{2}{*}{$\begin{array}{l}\text { ANOVA } \\
\text { p value }\end{array}$} & \multirow{2}{*}{$\begin{array}{l}\text { Chi } \\
\text { squared p } \\
\text { value }\end{array}$} & \multicolumn{2}{|c|}{$\begin{array}{c}\text { Point biserial } \\
\text { correlation } \\
\text { coefficient }\end{array}$} \\
\hline & & & & & $\mathbf{r}$ & p Value \\
\hline DRD2 & rs 1800497 & $\mathrm{~T}$ & 0.30 & 0.95 & -0.03 & 0.41 \\
\hline DRD2 & Taq1A & - & 0.40 & 0.99 & 0.23 & 0.08 \\
\hline DRD2 & rs 6277 & $\mathrm{~T}$ & 0.97 & NA & NA & NA \\
\hline DRD2 & rs 12364283 & $\mathrm{C}$ & 0.91 & 0.74 & -0.03 & 0.41 \\
\hline DRD3 & rs6280 & $\mathrm{C}$ & 0.98 & NA & NA & NA \\
\hline DRD4 & VNTR & 2 & 0.94 & 0.99 & NA & NA \\
\hline SLC6A3/DAT1 & VNTR & 10 & 0.56 & 0.60 & NA & NA \\
\hline COMT & rs 4680 & $\mathrm{G}$ & 0.76 & 0.99 & -0.1 & 0.27 \\
\hline COMT & rs 4818 & G & 0.90 & 0.99 & -0.02 & 0.46 \\
\hline MAOA & VNTR & 4 & 0.66 & 0.57 & NA & NA \\
\hline MAOB & rs 1799836 & A & 0.61 & 0.81 & 0.12 & 0.18 \\
\hline
\end{tabular}

Table 4-6. Dose dependent comparison of genotype percent weight change.

\begin{tabular}{|c|c|c|c|c|c|c|}
\hline \multirow[b]{2}{*}{ Gene } & \multirow[b]{2}{*}{ Variant } & \multirow[b]{2}{*}{$\begin{array}{l}\text { Risk } \\
\text { allele }\end{array}$} & \multirow[b]{2}{*}{$\begin{array}{l}\text { ANOVA } \\
\text { p value }\end{array}$} & \multirow{2}{*}{$\begin{array}{l}\text { Chi } \\
\text { squared } \\
\text { p value }\end{array}$} & \multicolumn{2}{|c|}{$\begin{array}{c}\text { Point biserial } \\
\text { correlation } \\
\text { coefficient }\end{array}$} \\
\hline & & & & & $\mathbf{r}$ & p Value \\
\hline DRD2 & rs 1800497 & $\mathrm{~T}$ & 0.18 & 0.92 & -0.28 & 0.05 \\
\hline DRD2 & Taq1A & - & 0.33 & 0.94 & -0.24 & 0.06 \\
\hline DRD2 & rs 6277 & $\mathrm{~T}$ & 0.96 & 0.99 & NA & NA \\
\hline DRD2 & rs 12364283 & $\mathrm{C}$ & 0.91 & 0.74 & -0.03 & 0.41 \\
\hline DRD3 & rs 6280 & $\mathrm{C}$ & 0.99 & 0.96 & NA & NA \\
\hline DRD4 & VNTR & 2 & 0.91 & 0.97 & NA & NA \\
\hline SLC6A3/DAT1 & VNTR & 10 & 0.56 & 0.18 & NA & NA \\
\hline COMT & rs4680 & $\mathrm{G}$ & 0.92 & 0.99 & -0.06 & 0.30 \\
\hline COMT & rs4818 & $\mathrm{G}$ & 0.82 & 0.98 & -0.04 & 0.41 \\
\hline MAOA & VNTR & 4 & 0.72 & 0.70 & NA & NA \\
\hline MAOB & rs 1799836 & $\mathrm{~A}$ & 0.49 & 0.82 & 0.12 & 0.16 \\
\hline
\end{tabular}




\section{Comparison of Genotype by Risk Allele}

This analysis takes into account the nature of the risk allele and increases power by collapsing categories based upon risk allele. For instance, if the risk allele is A, then heterozygotes and homozygous AA individuals are compared as one group to those individuals homozygous for the other alleles. Although none of the comparisons were statistically significant $(\mathrm{p} \leq 0.05)$, several variants approach a level of significance that warrants continued consideration $(\mathrm{p} \leq 0.20$, i.e. the SLC6A3/DAT1 VNTR, the Taq1A SNP, and the DRD4 VNTR) (Table 4-7).

\section{Effect Sizes: Odds Ratios, Risk Ratios, Cohen's $d$}

Odds ratios, risk ratios, and Cohen's $d$ were then calculated for each variant to estimate an effect size for the risk alleles. Homozygous and heterozygous risk alleles were combined and compared to those homozygous for other alleles. To quantify the disease process, individuals that gained greater than $5 \%$ of their baseline weight were compared to individuals that lost weight, stayed the same, or had insignificant weight gains in the 12 months after kidney transplantation, and percent weight change was used in a continuous fashion for Cohen's $d$ analysis. Effect sizes were small to moderate at best, and while risk and odds ratios may at first glance appear to be impressive, it is important to note that these can be somewhat misleading in a small sample size (Table 4-8).

\section{Regression Modelling}

The regression model was built in a step wise fashion, first with demographic characteristics, then demographic characteristics and one genetic variant, then all genetic variants, then all demographic and all genetic variants. In order to be entered into any regression model, the genetic variants had to attain a $\mathrm{p} \leq 0.20$ in previous statistical analyses (Bursac et al., 2008). Based upon this criteria, the following genetic variants were included in the regression modelling: rs1800497 SNP, Taq1A SNP, DRD4 VNTR, SLC6A3/DAT1 VNTR, and rs1799836 SNP. Each model calculated varied slightly in sample size, due to incomplete genotyping for some variants.

The regression model with only demographic factors (age, race, gender) and percent weight change included 66 subjects with complete data. This model approached significance with $\mathrm{p}=0.055$, and explained $11.4 \%$ of the variance in percent weight change. The only significant variable in the model was age, with a p value of 0.009 .

Regression models with all demographic characteristics and one genetic variant were nonsignificant. Subjects included in each model varied between 61 to 66 subjects due to incomplete genotyping data. Age was the only consistently significant demographic characteristic $(0.004 \leq \mathrm{p} \leq 0.02)$. A simple linear regression on age only was significant $(\mathrm{p}=0.006)$ and explained $11.2 \%$ of the variance in percent weight gain $(n=66)$. 
Table 4-7. Comparison of genotype by risk allele.

\begin{tabular}{|c|c|c|c|c|c|c|}
\hline \multirow[b]{2}{*}{ Gene } & \multirow[b]{2}{*}{ Variant } & \multirow[b]{2}{*}{$\begin{array}{l}\text { Risk } \\
\text { allele }\end{array}$} & \multirow[b]{2}{*}{$\begin{array}{l}\text { ANOVA } \\
\text { p value }\end{array}$} & \multirow{2}{*}{$\begin{array}{l}\text { Chi } \\
\text { squared } \\
\text { p value }\end{array}$} & \multicolumn{2}{|c|}{$\begin{array}{c}\text { Point biserial } \\
\text { correlation } \\
\text { coefficient }\end{array}$} \\
\hline & & & & & $\mathbf{r}$ & p Value \\
\hline DRD2 & rs1800497 & $\mathrm{T}$ & 0.36 & 0.99 & 0.04 & 0.36 \\
\hline DRD2 & Taq1A & - & 0.18 & 0.96 & 0.12 & 0.18 \\
\hline DRD2 & rs6277 & $\mathrm{T}$ & 0.39 & 0.99 & -0.04 & 0.39 \\
\hline DRD2 & rs 12364283 & $\mathrm{C}$ & 0.29 & 0.98 & -0.05 & 0.33 \\
\hline DRD3 & rs6280 & $\mathrm{C}$ & 0.50 & 0.96 & 0 & 0.50 \\
\hline DRD4 & VNTR & 2 & 0.17 & 0.85 & 0.13 & 0.15 \\
\hline SLC6A3/DAT1 & VNTR & 10 & 0.19 & 0.99 & 0.1 & 0.20 \\
\hline COMT & rs4680 & $\mathrm{G}$ & 0.40 & 0.99 & -0.03 & 0.40 \\
\hline COMT & rs4818 & $\mathrm{G}$ & 0.28 & 0.99 & -0.07 & 0.28 \\
\hline MAOA & VNTR & 4 & 0.33 & 0.96 & -0.05 & 0.33 \\
\hline MAOB & rs 1799836 & A & 0.25 & 0.99 & -0.08 & 0.25 \\
\hline
\end{tabular}

Table 4-8. Risk ratio, odds ratio, and effect size for each variant.

\begin{tabular}{lllll}
\hline Gene & Variant & Risk ratio & Odds ratio & Cohen's $\boldsymbol{d}$ \\
\hline DRD2 & rs1800497 & 1.08 & 1.13 & 0.09 \\
DRD2 & Taq1A & 1.40 & 1.69 & 0.23 \\
DRD2 & rs6277 & 0.98 & 0.97 & -0.07 \\
DRD2 & rs12364283 & 0.81 & 0.72 & -0.20 \\
DRD3 & rs6280 & 1.44 & 1.69 & 0.002 \\
DRD4 & VNTR & 1.84 & 2.96 & 0.41 \\
SLC6A3/DAT1 & VNTR & 0.08 & 1.8 & 0.47 \\
COMT & rs4680 & 0.95 & 0.92 & -0.08 \\
COMT & rs4818 & 0.93 & 0.89 & -0.15 \\
MAOA & VNTR & 1.31 & 1.5 & -0.11 \\
MAOB & rs1799836 & 0.94 & 0.91 & -0.16 \\
\hline
\end{tabular}


The regression model using only genetic variants was nonsignificant $(n=53$, $\mathrm{p}=0.56$ ), as was the regression model using all demographic factors and all genetic variants $(n=53, p=0.57)$. However, some of the regressors in the latter model had $p$ values that approached significance, such as age $(p=0.14)$, the SLC6A3/DAT1 9/10 genotype $(p=0.12)$, and the SLC6A3/DAT1 10/10 genotype $(p=0.13)$. This information, combined with the significance of the DRD2 SNP rs1800497 from the dose dependent comparison of genotype with percent weight change $(\mathrm{r}=-0.28, \mathrm{p}=0.05)$, lead to an exploratory regression model built with just the following characteristics: age, DRD2 SNP rs1800497 genotype, and SLC6A3/DAT1 VNTR genotype. This model was not significant ( $\mathrm{n}=53$, $\mathrm{p}=0.23$ ), and no regressors in the model were significant.

No individuals had a percent change in body weight that was more than \pm 3 standard deviations from the mean (mean percent weight change $=1.37 \pm 11.62 \%$, maximum percent weight change $=33.47$, minimum percent weight change $=-22.19$ ). Outliers for regression modeling were thus defined under more stringent criteria of \pm 2 standard deviations from the mean. The following regression models were then constructed with these 3 outliers eliminated: demographics only, demographics and all genetic variants, and the exploratory age, SLC6A3/DAT1, and DRD2 SNP rs1800497. No meaningful changes were associated with the removal of the outlier subjects for these models. For the demographic only model, the $p$ value changed from 0.055 to 0.058 . For the demographics and all genetic variants model, the $\mathrm{p}$ value changed from 0.57 to 0.56 . For the exploratory age, SLC6A3/DAT1, and DRD2 SNP rs1800497 model, the p value changed from 0.23 to 0.30 .

\section{Haplotype Analysis}

Haplotype analyses were attempted for DRD2 and COMT variants, the two genes that were tested for more than one variant. The DRD2 variants (rs1800497, rs6277, and rs12364283) showed promising results using Haploview software (Barrett, Fry, Maller, \& Daly, 2005). This software found that rs 1800497 and rs6277 are inherited together 3\% of the time, and rs1800497 and rs12364283 are inherited together 34\% of the time for this sample. These variants had disparate minor allele frequencies ranging from 0.066 to 0.318 , which limited the value of $D^{\prime}$ and $r^{2}$ calculations. Since it appeared that these variants were not in linkage disequilibrium, further analysis was planned for this gene. Unfortunately, this plan was curtailed as the sample size per haplotype cell was too small to continue.

For COMT, the two variants are $70 \mathrm{~kb}$ apart and in linkage disequilibrium. No further haplotype analysis of these variants was done, as this would not provide any additional information. 


\section{Power Analysis}

This pilot study was conducted to estimate the feasibility and validity of extending this work in a larger population and as such was not expected to meet criteria for $80 \%$ power with an alpha of 0.1 . A post hoc power analysis for each SNP resulted in power ranging from 0.10 to 0.12 , with the number of subjects needed for $80 \%$ power ranging from 1058 to 9565 (Table 4-9). The power analysis for the VNTRs ranged from 0.11 to 0.40 , with the number of subjects needed for $80 \%$ power ranging from 81 to 2658 .

\section{Discussion}

This study was conducted to evaluate the association of dopaminergic polymorphisms and demographic characteristics with 12 month weight gain in kidney transplant recipients. These kidney transplant recipients are an ideal model population for the study of weight gain, as they are likely to gain a substantial amount of weight in the first year after transplantation. However, since not all kidney transplant recipients gain weight, they provide the desired phenotypic variability to associate with individual genetic variability. In this sample, 25 people gained greater than $5 \%$ of their pretransplant body weight, 20 people stayed within $\pm 5 \%$ of their pretransplant body weight, and 25 people lost greater than $5 \%$ of their pretransplant body weight. This supports previously reported findings that a minimum of $1 / 3$ of all kidney transplant recipients will gain a significant amount of weight in the first year following transplantation (Cashion et al., 2007; Clunk et al., 2001; Jezior et al., 2007).

It is important to note that a change in weight does not necessarily signify that an individual became obese (Figure 4-1). Many individuals stayed in the same weight classification, while others lost weight. Only four individuals gained enough weight to become newly classified as obese. Unless the subject was severely underweight at the time of transplant, any within subject weight gain could potentially become problematic and over time lead to obesity. No individual included in this study was underweight at the time of transplant. One subject was categorized as normal weight at the time of transplant, but lost weight and was classified as underweight at 12 months post-transplant (baseline $\mathrm{BMI}=19.91,12$ month $\mathrm{BMI}=17.15$ ).

Overall, for this sample no significant change was observed from baseline to 12 months for mean weight change $(p=0.29)$ or BMI $(p=0.27)$. This was not surprising, as the weight change of interest was evaluated on a within subject basis. Therefore, failure to see a difference in the mean weight change from baseline to 12 months demonstrates the variability of weight change in the sample, which benefitted the design of the study.

The only genetic variant tested that was found to be independently and significantly associated with percent weight change was the DRD2 promoter region SNP rs $1800497(r=-0.28, p=0.05)$. This association occurred in a dose dependent manner, indicating that the genotype TT is different than either the TC or CC genotype in its correlation with percent weight change of kidney transplant recipients at 12 months. This 
Table 4-9. Post hoc power and sample size calculations.

\begin{tabular}{llll}
\hline Gene & Variant & Power for current N & N needed for 80\% power \\
\hline DRD2 & rs1800497 & 0.10 & 40369 \\
DRD2 & Taq1A & 0.12 & 1058 \\
DRD2 & rs6277 & 0.10 & 6587682 \\
DRD2 & rs12364283 & 0.11 & 5120 \\
DRD3 & rs6280 & 0.10 & 7246 \\
DRD4 & VNTR & 0.40 & 81 \\
SLC6A3/DAT1 & VNTR & 0.11 & 2658 \\
COMT & rs4680 & 0.10 & 9565 \\
COMT & rs4818 & 0.10 & 56868 \\
MAOA & VNTR & 0.35 & 98 \\
MAOB & rs1799836 & 0.12 & 1352 \\
\hline
\end{tabular}




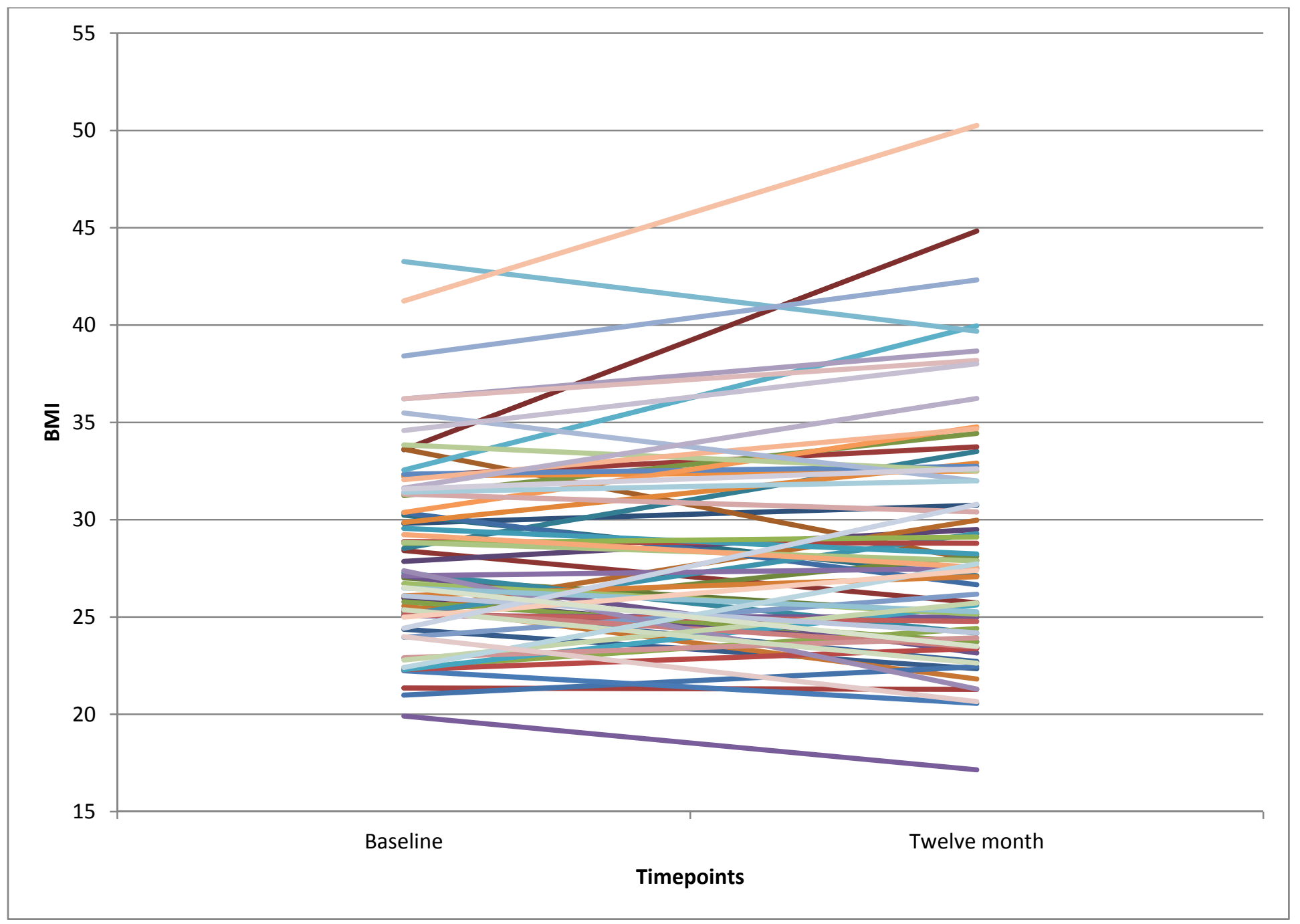

Figure 4-1. Subject trendlines for BMI at baseline and twelve months' post-transplant. 
result was found despite a power of only $10 \%$ and an effect size $d=0.09$, attesting to the strength of this allele's influence on weight gain. This finding is consistent with previous reports that have shown that the $\mathrm{C}$ allele is associated with higher numbers of $\mathrm{D} 2$ receptors in the brain (Jonsson et al., 1999), and with increased BMI (Jenkinson et al., 2000). Further support for our results comes from work showing that a dose dependent reduction in $\mathrm{D} 2$ receptors (from the T allele) is proportional to the increase in BMI (G. J. Wang et al., 2001).

Furthermore, the rs 1800497 SNP is located in a promoter region for the DRD2 gene. Changes in this control region can result in large changes in transcriptional activity of the gene. Most importantly, the expression of the gene can be vastly altered either up or down from wild type levels. The fact that this SNP was found to be associated with percent change in this study also supports the results of previous work in the transplant population. Changes in expression levels of this gene in adipose tissue of 26 kidney transplant recipients were significantly associated with weight gain at six months posttransplant (Cashion et al., 2013). The association of these expression changes in such a small sample could be the result of this SNP's promoter region effects, or it could be due to an over representation of the TT genotype in kidney transplant recipients

If the TT genotype is over represented, it could be due to population stratification for this allele. This sample is not in Hardy Weinberg equilibrium for four of the variants tested: DRD2 rs6277, DRD2 rs12364283, DRD3 rs6280, and MAOB rs1799836. This may be the result of a small sample size, as calculations for Hardy Weinberg equilibrium are not entirely accurate unless there are greater than 5 individuals for each genotype (Court, 2008). However, some of the violation of HWE could also reflect a true population stratification, possibly related to differences in ancestry. This sample was heterogeneous in racial background, making it likely there is a representation of several different ancestral lines that each contain different major and minor allele frequencies. For example, the DRD2 SNP rs6277 has a minor C allele frequency of 0.396 in Caucasian populations, while African American populations have a minor allele frequency of 0.913 (HapMap, February 2014, GRCh38).

Another explanation for potential population stratification could lie in the characteristics of individuals who may be more prone to become a candidate for kidney transplantation. To the best of our knowledge, there is no known relationship between dopamine and kidney transplantation. However, it is possible that there could be some inherent dopaminergic related behaviors that when present in individuals with kidney disease, increase the likelihood that they will require a transplant. Perhaps a reduction in dopaminergic reward from certain behaviors could be related to a reduction in health promoting behaviors. Over time, this could lead to an increased likelihood of kidney failure and the need for transplantation, thereby resulting in an over-selection for this genotype when sampling kidney transplant recipients.

The demographic characteristics evaluated in this study were age, race, and gender. In our sample, race and gender were not found to be associated with weight gain at 12 months. Although the correlation between age and percent weight change was not 
robust $(\mathrm{r}=-0.32, \mathrm{p}=0.007)$, a significant association remained across all regression models that were attempted with and without genetic factors. A simple linear regression with age was highly significant $(\mathrm{p}=0.006)$, and explained $11.2 \%$ of the variance in post-transplant percent weight change. The fact that this one factor consistently remained influential for weight gain (which is controlled by a host of other variables) is worth noting. It has been suggested that older African American women were the most likely to gain weight after transplantation (Cashion et al., 2007; Clunk et al., 2001). But in our sample we only found age to be a contributing factor, with less weight gain associated with increasing age.

A regression model with only demographic factors (age, race, gender) and percent weight change accounted for $11.4 \%$ of the variance in percent weight change $(\mathrm{p}=0.055)$, with age being the only significant contributor $(\mathrm{p}=0.009)$. Our small sample size may have influenced the difference in our results and those reported in the literature. However, it is also possible that the inclusion of outlier subjects who gained or lost extreme amounts of weight skewed the mean. No outliers were more than \pm 3 standard deviations from the mean, therefore the more stringent cut-point of \pm 2 standard deviations from the mean was used to define outliers. This cut point removed three subjects, and resulted in a model that was very similar to that with outliers included. The model explained $11.8 \%$ of the variance in percent weight change $(\mathrm{p}=0.058)$. The only significant contributor was again age $(\mathrm{p}=0.011)$.

Regression models built with demographic characteristics and one genetic variant were all nonsignificant (Table 4-10). These models vary in sample size, due to incomplete genotype data for some variants. Although the overall models were all nonsignificant, age was a significant variable for every model tested, with $\mathrm{p}$ values ranging from 0.004 in the DRD4 model to 0.02 in the rs 1800497 model.

A larger regression composed of only the five genetic variables was nonsignificant $(\mathrm{p}=0.56$ ), but explained $25 \%$ of the variance in percent weight change post kidney transplant. This is a substantial increase in the strength compared to the demographic only model, suggesting that a large portion of the variability is in fact due to genetic factors. However, none of the five genetic variants (rs1800497,Taq1A, DAT1, DRD4, and rs1799836) were significant as individual regressors. This may suggest that the small to moderate effect sizes for each variant make it difficult to capture an individual significant result. Additionally, the inherently modest effect sizes are compounded by also having a very small sample size, creating an overall reduction in power. The sample size used for this regression model was reduced to the 53 subjects with complete genotype data for all five variants. It is therefore possible that a larger sample size could result in a significant result, particularly for SLC6A3/DAT1 9/10 and DRD2 rs1800497 AG genotypes which approached significance $(\mathrm{p}=0.08$ and 0.07 respectively).

All demographic characteristics (age, race, gender) and all five genetic variants (rs1800497, Taq1A, SLC6A3/DAT1, DRD4, and rs1799836) were included in the largest regression model $(\mathrm{n}=53)$. This model was nonsignificant $(\mathrm{p}=0.57)$, and none of the 
Table 4-10. Regression models for individual variants and demographic characteristics.

\begin{tabular}{lllll}
\hline Gene & Variant & Sample size & p Value & $\mathbf{R}^{\mathbf{2}}$ \\
\hline DRD2 & rs1800497 & 62 & 0.10 & 0.15 \\
DRD2 & Taq1A & 63 & 0.14 & 0.13 \\
DRD4 & VNTR & 61 & 0.23 & 0.17 \\
SLC6A3/DAT1 & VNTR & 64 & 0.20 & 0.17 \\
MAOB & rs1799836 & 66 & 0.13 & 0.13 \\
\hline
\end{tabular}


individual regressors were significant, although several variables had $\mathrm{p}$ values that warrant further exploration in a larger sample, such as age $(\mathrm{p}=0.14)$, SLC6A3/DAT1 9/10 genotype $(\mathrm{p}=0.12)$, and the SLC6A3/DAT1 10/10 genotype $(\mathrm{p}=0.13)$. The same model was tested with the three outliers \pm 2 standard deviations from the mean removed, and although the model was still nonsignificant $(\mathrm{p}=0.56)$, the SLC6A3/DAT1 9/10 genotype and the SLC6A3/DAT1 10/10 genotype approached significance as regressors $(\mathrm{p}=0.056$ and $\mathrm{p}=0.061$ respectively).

As an exploratory exercise, a regression model was built with variables that had $\mathrm{p}$ values $\leq 0.20$ as regressors in previous models. This included age, SLC6A3/DAT1 genotype, and DRD2 rs 1800497 genotype. This model was nonsignificant ( $\mathrm{n}=53$, $\mathrm{p}=0.24$ ), and the individual regressors were nonsignificant as well. The removal of outliers did not improve the model $(\mathrm{p}=0.30)$. Again, it is possible that a larger sample size could have pushed these genotypes into the realm of statistical significance.

The lack of statistical significance among individual variants in the regression models suggests that there may be an additive or multiplicative effect among various risk alleles. Although these variants are located on different genes, a haplotype inheritance of the whole group of risk alleles could be the important factor. Unfortunately, sample size limitations in this study did not allow this type of subgroup analysis.

Even though these results are intriguing, there still remains a large percentage of the variance in post-transplant weight gain that is not accounted for. It is possible that although the variants built into the model are important in determining post-transplant weight gain, these variants do not capture all of the relevant biological pathways for this

outcome. This possibility paves the way for future work in discovering what other genetic polymorphisms may predispose kidney transplant recipients to gain weight in the first year after surgery.

\section{Limitations}

This study was conducted as a pilot study to test the methodology and the feasibility in extending the study to a larger sample. As such, the study was grossly underpowered, primarily due to a limited sample size and as such produced only small to moderate effect sizes. This lack of generalizability was expected, as this study was done to test feasibility of the methodology. Generalizability was also reduced by the demographic characteristics of the sample being representative of the Caucasian and African American populations, but not of kidney transplant recipients of other racial and ethnic backgrounds.

Another limitation for this study was that within gene variation was not completely sampled. While many of the most widely studied variants were tested, this study did not have an exhaustive list. Additionally, there could be other regions of variation within these genes that simply have not been widely studied yet, and so were 
not sampled in this study. Furthermore, weight gain is a complex disorder, with numerous influential factors that cannot be completely accounted for or controlled.

Despite these limitations, the study method worked well, as suggested by independent validation of polymorphism in DRD2. Taq1A and rs1800497 are the same variant within the DRD2 gene, and provide an opportunity to validate laboratory procedures. The Taq1A was measured using a RFLP method, while the rs 1800497 was measured using a commercial PCR based kit. The results were reasonably consistent, confirming the validity of study methods. Additionally, although the overall regression models were not in themselves significant, significant results were seen for age and rs1800497, and results approaching significance were seen for the SLC6A3/DAT1 9/10 genotype.

\section{Conclusions}

This study was conducted to assess the value of dopaminergic polymorphisms and demographic characteristics (age, race, and gender) on predicting weight gain at 12 months' post kidney transplantation. Although the results are somewhat tempered by the small sample size that was used for this pilot study, the most robust predictor of posttransplant weight gain was age at time of transplantation. The DRD2 SNP rs1800497 and SLC6A3/DAT1 VNTR genotypes show promising but inconsistent results. Replications of this same work with a larger sample size should be done to fully assess the contributions of these genotypes to prediction of post-transplant weight gain. 


\section{CHAPTER 5. IMPLICATIONS FOR PRACTICE AND FUTURE RESEARCH}

\section{Introduction}

This chapter synthesizes the results presented in Chapter 4, and based upon these results, suggests modifications to be made to the conceptual model presented in Chapter 1. This chapter then makes suggestions for clinical practice and future research to expand upon the results seen.

\section{Modifications to Conceptual Model}

In chapter 1, a conceptual model was proposed based upon the literature on weight gain, kidney transplantation, and dopamine (Figure 1-1). Several changes are proposed to modify that conceptual model based upon the findings of this study (Figure 5-1).

The first modification to the conceptual model is to alter the outcome measure from "post-transplant weight gain" to "post-transplant percent weight change". This change should be made because the concept of percent weight change has greater clinical utility. The clinical implications of weight change are variable depending on stature and gender, i.e. a 5 pound weight change for a 5 ' tall woman is quite different than a 5 pound weight change for a 6' tall man. Therefore, raw weight gain in pounds is not an accurate representation of the physiologic changes going on for the individual. Percent weight change captures some of this variation.

The second modification to the conceptual model should be to change the "personality and reward brain regions" spoke of the wheel to "reward brain regions". A greater understanding of the mesolimbocortical pathways indicates that these regions, while they do to some extent relate to a hedonistic type personality, have a much stronger relationship with reward of behaviors. This reward mechanism most distinctly relates to weight gain, rather than an overall personality type predisposing individuals towards obesity.

A third modification to the conceptual model is to alter the demographic and genetic characteristics shown. However, this change should only be made after results are confirmed or refuted in a larger sample size. In this study, only age, DRD2 rs1800497 genotype, and SLC6A3/DAT1 VNTR genotype were shown to have any value in weight gain after kidney transplantation. It could be argued that the remaining characteristics should be removed from the conceptual model. However, this study was conducted as a pilot, with a small sample size. The study should be repeated in a larger sample size, and possibly with a larger portion of the variation within the targeted genes captured (through the expansion of the variants tested), before any of these modifications should be made. 


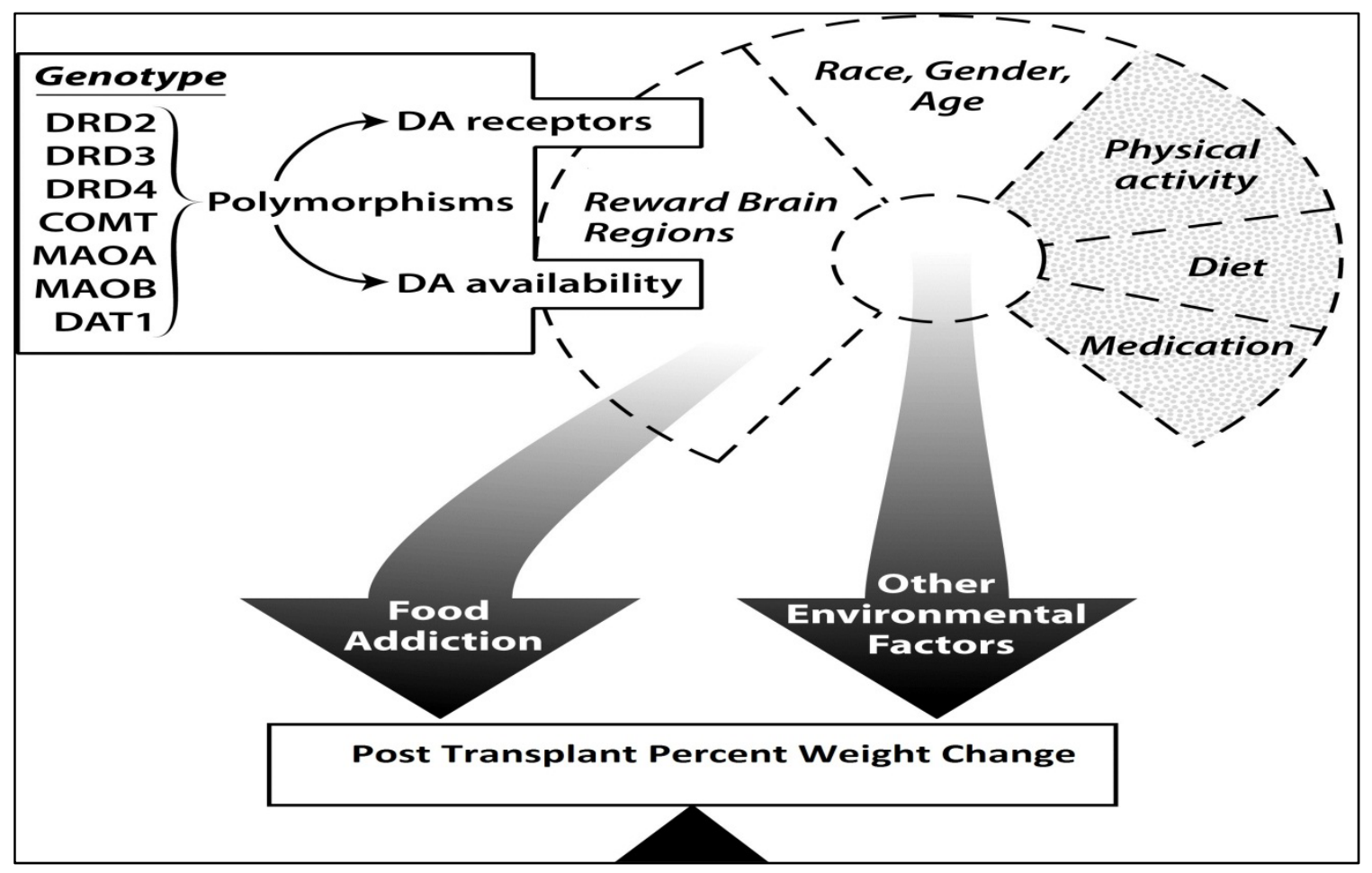

Figure 5-1. Modifications to conceptual model. 


\section{Implications for Practice}

Although not ready for immediate clinical use, the results of this study pave the way for clinical testing that will help identify individuals most at risk of gaining weight. Ultimately, these individuals could be targeted for more aggressive interventions aimed at reducing the impact of environmental factors on weight gain. Any interventions that can moderate the amount of weight gained after transplantation are likely to have enormous health benefits by reducing the likelihood of developing comorbidities, such as cardiovascular disease and diabetes which are the major causes of death following kidney transplantation.

While interventions aimed at reducing caloric intake and increasing physical activity have value, it is unclear exactly what interventions may be most useful for long term weight loss in genetically at-risk individuals. One recent study has shown that individuals homozygous for the risk allele of DRD2 rs 1800497 may be resistant to certain weight loss strategies (Roth, Hinney, Schur, Elfers, \& Reinehr, 2013). More research is needed to most effectively target individuals of this genotype.

While the results of this study are most obviously important for kidney transplant recipients, they may also be of value in non-transplant populations. Certainly other at-risk populations could benefit from targeted weight loss interventions. Further work would need to be done to validate the findings of this study in additional populations.

This research also has implications for the study of obesity in general. Previously, much research has focused on more obvious genetic targets for weight gain, such as the hormones leptin and ghrelin (Keen-Rhinehart, Ondek, \& Schneider, 2013; Suzuki, Jayasena, \& Bloom, 2012). While these types of targets have value, there is still a large amount of variance in weight gain that has yet to be explained. Even large genome wide association studies (GWAS) have not been able to capture the total variance with these types of targets (Xia \& Grant, 2013). The increase in research relating weight gain to dopaminergic genes can help account for some of this variation. Furthermore, the study of the relationship of dopamine to weight gain changes the focus from endocrine factors to neurological/psychological factors. This opens the door for the discussion of food addiction, a hypothesis that is continuing to gain support in the literature (Gearhardt \& Corbin, 2011; Ziauddeen et al., 2012).

\section{Future Directions}

The conceptual basis for this study continues to be relevant to the state of the science (Kenny, Voren, \& Johnson, 2013; Volkow et al., 2013). As such, this work should be repeated in a larger sample size. Larger sample sizes will increase power and also make subgroup analysis possible, particularly by comorbidities such as diabetes, by gender, or by racial and/or ethnic backgrounds (Bamshad, Wooding, Salisbury, \& Stephens, 2004; Caulfield et al., 2009). Subgrouping analysis may help to clarify the potential for population stratifications inherent to a kidney transplant population. 
Furthermore, subgroup analysis can increase the ability to detect significant associations. This is especially true for associations that may only have value within certain subgroups.

A greater sample size would also allow haplotype analysis for the variants in DRD2 and in COMT. The current study did not have a large enough sample size to account for many of the possible haplotypes associated with the variants tested. Yet haplotype analysis can be useful as it is often the inheritance of a given haplotype of alleles, not the inheritance of just one particular allele, which increases the risk for a given genetic disorder. An example of this type of inheritance is shown in estrogen genes related to obesity (Goulart, Zee, \& Rexrode, 2009).

Another future direction for research is to expand the number of variants tested in each of the dopaminergic genes. Since the genetic-only regression model accounted for $25 \%$ of the variance in post-transplant weight gain, it seems reasonable that the variants selected in future studies be expanded to capture more of the variation in dopaminergic genes. It is especially useful to consider expanding the variants tested for DRD2 and SLC6A3/DAT1, as these genes were shown to have the greatest promise for significant associations with weight gain. It may also be of value to consider other genes in the dopaminergic pathway that were not tested in the current study, such as the dopamine receptor type 1 gene, although any associations with obesity may be confounded with alterations in physical activity levels (Roberts et al., 2012).

Outside of dopaminergic pathways, other neurotransmitter genes may also have value in the study of obesity. One strong candidate is neuropeptide Y (NPY) (KeenRhinehart et al., 2013). When levels of NPY are artificially increased in rats, feeding behavior is also increased (Bi, Kim, \& Zheng, 2012). This dynamic is especially pronounced when the ventral tegmental area of the mesolimbic pathway is injected (Pandit, Luijendijk, Vanderschuren, la Fleur, \& Adan, 2014). But more importantly for the current line of inquiry, two NPY receptor genes (NPY1R and NPY5R) have also been shown to have expression changes associated with weight gain in adipose tissue of kidney transplant population (Cashion et al., 2013). It is possible that these genes could also have polymorphisms that explain the expression changes seen, and thus explain a portion of the missing variation in post-transplant weight gain.

Another likely candidate for future genetic work is the carboxypeptidase $\mathrm{E}$ gene (CPE). This enzyme removes amino acids from the $\mathrm{C}$ terminal of proteins. Most importantly to weight gain, coactivation of CPE and SLC6A3/DAT1 can cause amino acids to be removed from the $\mathrm{C}$ terminus of the dopamine transporter $(\mathrm{H}$. Zhang et al., 2009). This change results in hyperactivity of the dopamine transporter, leading to increased dopamine uptake from the synapse (H. Zhang et al., 2009). Over time, this coactivation could then possibly lead to altered eating behaviors. Indeed, expression changes in this gene have also been associated with weight gain in kidney transplant recipients (Cashion et al., 2013).

Alternatively, the dopaminergic pathway could be expanded to include serotonergic genes as well. These two systems are intimately interrelated for the 
rewarding properties of food. First, food cues cause dopamine to be released into the synapse. Later, during the consumption of food, serotonin binds to sites on the dopaminergic neurons to halt further release (Higgins, Sellers, \& Fletcher, 2013). It is thought that the serotonin acts as a stopgap towards continued consumption and thus promotes feelings of fullness (Higgins et al., 2013). As such, any serotonergic blocking agent is associated with increased weight by reducing feelings of fullness. Therefore, serotonin agonists have become potential targets for weight loss drugs (Higgins et al., 2013).

Much like dopamine, serotonergic genes have also polymorphisms that are associated with increased weight. Most recently, a SNP rs6314 of the serotonin receptor 2A gene has been associated with the effect of food reinforcement on BMI (Carr et al., 2013). Additionally, like dopamine, serotonin in the brain is degraded by MAOA, and so there may be a shared overlap in the significance of MAOA gene polymorphisms.

Finally, there is increasing evidence that continues to suggest a shared biological overlap for obesity and other types of addictive disorders (DiLeone, Taylor, \& Picciotto, 2012; Volkow, Wang, Tomasi, \& Baler, 2013). With the genetic and neuroimaging evidence mounting, future work should also extend the study of dopaminergic genetic contributions to substance abuse populations.

\section{Summary}

This chapter has provided modifications for the conceptual model proposed in Chapter 1, as well as providing suggestions for clinical implications of this work. Future work should expand upon the sample size, genotypes, and populations used in order to appropriately place this work within a greater scientific context. 


\section{LIST OF REFERENCES}

Abizaid, A., Gao, Q., \& Horvath, T. L. (2006). Thoughts for food: brain mechanisms and peripheral energy balance. Neuron, 51(6), 691-702.

Akarsu, M., Bakir, Y., Karademir, S., Unek, T., Bacakoglu, A., \& Astarcioglu, I. (2013). Prevalence and risk factors for obesity after liver transplantation: a single-center experience. Hepat Mon, 13(8), e7569.

Allison, D. B., Mentore, J. L., Heo, M., Chandler, L. P., Cappelleri, J. C., Infante, M. C., \& Weiden, P. J. (1999). Antipsychotic-induced weight gain: a comprehensive research synthesis. American Journal of Psychiatry, 156(11), 1686-1696.

Annerbrink, K., Westberg, L., Nilsson, S., Rosmond, R., Holm, G., \& Eriksson, E. (2008). Catechol O-methyltransferase val158-met polymorphism is associated with abdominal obesity and blood pressure in men. Metabolism: Clinical and Experimental, 57(5), 708-711.

Asghari, V., Sanyal, S., Buchwaldt, S., Paterson, A., Jovanovic, V., \& Van Tol, H. H. (1995). Modulation of intracellular cyclic AMP levels by different human dopamine D4 receptor variants. Journal of Neurochemistry, 65(3), 1157-1165.

Baik, J. H. (2013). Dopamine signaling in food addiction: role of dopamine D2 receptors. BMB Rep, 46(11), 519-526.

Balciuniene, J., Emilsson, L., Oreland, L., Pettersson, U., \& Jazin, E. (2002). Investigation of the functional effect of monoamine oxidase polymorphisms in human brain. Human Genetics, 110(1), 1-7.

Bamshad, M., Wooding, S., Salisbury, B. A., \& Stephens, J. C. (2004). Deconstructing the relationship between genetics and race. Nat Rev Genet, 5(8), 598-609.

Barrett, J. C., Fry, B., Maller, J., \& Daly, M. J. (2005). Haploview: analysis and visualization of LD and haplotype maps. Bioinformatics, 21(2), 263-265.

Barry, D., Clarke, M., \& Petry, N. M. (2009). Obesity and its relationship to addictions: is overeating a form of addictive behavior? American Journal on Addictions, 18(6), 439-451.

Bauer, F., Elbers, C. C., Adan, R. A., Loos, R. J., Onland-Moret, N. C., Grobbee, D. E., . .. van der Schouw, Y. T. (2009). Obesity genes identified in genome-wide association studies are associated with adiposity measures and potentially with nutrient-specific food preference. American Journal of Clinical Nutrition, 90(4), 951-959.

Baum, C. L. (2001). Weight gain and cardiovascular risk after organ transplantation. JPEN J Parenter Enteral Nutr, 25(3), 114-119.

Bello, N. T., Lucas, L. R., \& Hajnal, A. (2002). Repeated sucrose access influences dopamine D2 receptor density in the striatum. Neuroreport, 13(12), 1575-1578.

Bello, N. T., Sweigart, K. L., Lakoski, J. M., Norgren, R., \& Hajnal, A. (2003).

Restricted feeding with scheduled sucrose access results in an upregulation of the rat dopamine transporter. Am J Physiol Regul Integr Comp Physiol, 284(5), R1260-1268.

Bi, S., Kim, Y. J., \& Zheng, F. (2012). Dorsomedial hypothalamic NPY and energy balance control. Neuropeptides, 46(6), 309-314. 
Blum, K., Chen, A. L., Oscar-Berman, M., Chen, T. J., Lubar, J., White, N., . . Bailey, J. A. (2011). Generational association studies of dopaminergic genes in reward deficiency syndrome (RDS) subjects: selecting appropriate phenotypes for reward dependence behaviors. Int J Environ Res Public Health, 8(12), 4425-4459.

Blum, K., \& Gold, M. S. (2011). Neuro-chemical activation of brain reward meso-limbic circuitry is associated with relapse prevention and drug hunger: a hypothesis. Medical Hypotheses, 76(4), 576-584.

Blum, K., Liu, Y., Shriner, R., \& Gold, M. S. (2011). Reward circuitry dopaminergic activation regulates food and drug craving behavior. Current Pharmaceutical Design, 17(12), 1158-1167.

Bluml, V., Kapusta, N., Vyssoki, B., Kogoj, D., Walter, H., \& Lesch, O. M. (2012). Relationship between substance use and body mass index in young males. American Journal on Addictions, 21(1), 72-77.

Bureau, U. S. C. (2011). The Black Population: 2010.

Bursac, Z., Gauss, C. H., Williams, D. K., \& Hosmer, D. W. (2008). Purposeful selection of variables in logistic regression. Source Code Biol Med, 3, 17.

Caldu, X., Vendrell, P., Bartres-Faz, D., Clemente, I., Bargallo, N., Jurado, M. A., . . . Junque, C. (2007). Impact of the COMT Val108/158 Met and DAT genotypes on prefrontal function in healthy subjects. Neuroimage, 37(4), 1437-1444.

Camarena, B., Santiago, H., Aguilar, A., Ruvinskis, E., Gonzalez-Barranco, J., \& Nicolini, H. (2004). Family-based association study between the monoamine oxidase A gene and obesity: implications for psychopharmacogenetic studies. Neuropsychobiology, 49(3), 126-129.

Capp, P. K., Pearl, P. L., \& Conlon, C. (2005). Methylphenidate HCl: therapy for attention deficit hyperactivity disorder. Expert Rev Neurother, 5(3), 325-331.

Carnell, S., Gibson, C., Benson, L., Ochner, C. N., \& Geliebter, A. (2012). Neuroimaging and obesity: current knowledge and future directions. Obes Rev, 13(1), 43-56.

Carr, K. A., Lin, H., Fletcher, K. D., Sucheston, L., Singh, P. K., Salis, R. J., . . Epstein, L. H. (2013). Two functional serotonin polymorphisms moderate the effect of food reinforcement on BMI. Behavioral Neuroscience, 127(3), 387-399.

Cashion, A., Hathaway, D., Stanfill, A., Thomas, F., Ziebarth, J., Cui, Y., . . . Eason, J. (2014). Pre-transplant predictors of one year weight gain after kidney transplantation. Clinical Transplantation.

Cashion, A., Sánchez, Z., Cowan, P., Hathaway, D., Costello, A., \& Gaber, A. (2007). Changes in weight during the first year after kidney transplantation. Progress in Transplantation, 17(1), 40-47.

Cashion, A., Stanfill, A., Thomas, F., Xu, L., Sutter, T., Eason, J., . . Homayouni, R. (2013). Expression levels of obesity-related genes are associated with weight change in kidney transplant recipients. PLoS One, 8(3), e59962.

Caulfield, T., Fullerton, S. M., Ali-Khan, S. E., Arbour, L., Burchard, E. G., Cooper, R. S., . . Daar, A. S. (2009). Race and ancestry in biomedical research: exploring the challenges. Genome Med, 1(1), 8.

Centers for Disease Control and Prevention. (2009). Health United States Retrieved July 25, 2011, from http://www.cdc.gov/nchs/data/hus/hus09.pdf

Clunk, J. M., Lin, C. Y., \& Curtis, J. J. (2001). Variables affecting weight gain in renal transplant recipients. Am J Kidney Dis, 38(2), 349-353. 
Comings, D. E., Gonzalez, N., Wu, S., Saucier, G., Johnson, P., Verde, R., \& MacMurray, J. P. (1999). Homozygosity at the dopamine DRD3 receptor gene in cocaine dependence. Molecular Psychiatry, 4(5), 484-487.

Cornoni-Huntley, J. C., Harris, T. B., Everett, D. F., Albanes, D., Micozzi, M. S., Miles, T. P., \& Feldman, J. J. (1991). An overview of body weight of older persons, including the impact on mortality. The National Health and Nutrition Examination Survey I--Epidemiologic Follow-up Study. Journal of Clinical Epidemiology, 44(8), 743-753.

Court, M. H. (2008). HW calculator.

Cupples, C. K., Cashion, A. K., Cowan, P. A., Tutor, R. S., Wicks, M. N., Williams, R., \& Eason, J. D. (2012). Characterizing dietary intake and physical activity affecting weight gain in kidney transplant recipients. Progress in Transplantation, 22(1), 62-70.

DiLeone, R. J., Taylor, J. R., \& Picciotto, M. R. (2012). The drive to eat: comparisons and distinctions between mechanisms of food reward and drug addiction. Nature Neuroscience, 15(10), 1330-1335.

Duan, J., Wainwright, M. S., Comeron, J. M., Saitou, N., Sanders, A. R., Gelernter, J., \& Gejman, P. V. (2003). Synonymous mutations in the human dopamine receptor D2 (DRD2) affect mRNA stability and synthesis of the receptor. Human Molecular Genetics, 12(3), 205-216.

Elster, E. A., Leeser, D. B., Morrissette, C., Pepek, J. M., Quiko, A., Hale, D. A., . . . Mannon, R. B. (2008). Obesity following kidney transplantation and steroid avoidance immunosuppression. Clinical Transplantation, 22(3), 354-359.

Faravardeh, A., Eickhoff, M., Jackson, S., Spong, R., Kukla, A., Issa, N., . . . Ibrahim, H. N. (2013). Predictors of graft failure and death in elderly kidney transplant recipients. Transplantation, 96(12), 1089-1096.

Frayling, T. M., Timpson, N. J., Weedon, M. N., Zeggini, E., Freathy, R. M., Lindgren, C. M., . . McCarthy, M. I. (2007). A common variant in the FTO gene is associated with body mass index and predisposes to childhood and adult obesity. Science, 316(5826), 889-894.

Galvao, A. C., Kruger, R. C., Campagnolo, P. D., Mattevi, V. S., Vitolo, M. R., \& Almeida, S. (2012). Association of MAOA and COMT gene polymorphisms with palatable food intake in children. J Nutr Biochem, 23(3), 272-277.

Gearhardt, A. N., \& Corbin, W. R. (2011). The role of food addiction in clinical research. Current Pharmaceutical Design, 17(12), 1140-1142.

Goulart, A. C., Zee, R. Y., \& Rexrode, K. M. (2009). Estrogen receptor 1 gene polymorphisms and decreased risk of obesity in women. Metabolism: Clinical and Experimental, 58(6), 759-764.

Hajnal, A., \& Norgren, R. (2002). Repeated access to sucrose augments dopamine turnover in the nucleus accumbens. Neuroreport, 13(17), 2213-2216.

Haltia, L. T., Rinne, J. O., Merisaari, H., Maguire, R. P., Savontaus, E., Helin, S., . . Kaasinen, V. (2007). Effects of intravenous glucose on dopaminergic function in the human brain in vivo. Synapse, 61(9), 748-756.

Heber, D., \& Carpenter, C. L. (2011). Addictive genes and the relationship to obesity and inflammation. Molecular Neurobiology, 44(2), 160-165. 
Heinz, A., Goldman, D., Jones, D. W., Palmour, R., Hommer, D., Gorey, J. G., . . . Weinberger, D. R. (2000). Genotype influences in vivo dopamine transporter availability in human striatum. Neuropsychopharmacology, 22(2), 133-139.

Higgins, G. A., Sellers, E. M., \& Fletcher, P. J. (2013). From obesity to substance abuse: therapeutic opportunities for 5-HT2C receptor agonists. Trends in Pharmacological Sciences, 34(10), 560-570.

Hirvonen, M., Laakso, A., Nagren, K., Rinne, J. O., Pohjalainen, T., \& Hietala, J. (2004). C957T polymorphism of the dopamine D2 receptor (DRD2) gene affects striatal DRD2 availability in vivo. Molecular Psychiatry, 9(12), 1060-1061.

Huang, W., Payne, T. J., Ma, J. Z., \& Li, M. D. (2008). A functional polymorphism, rs6280, in DRD3 is significantly associated with nicotine dependence in European-American smokers. Am J Med Genet B Neuropsychiatr Genet, 147B(7), 1109-1115.

Jeanneteau, F., Funalot, B., Jankovic, J., Deng, H., Lagarde, J. P., Lucotte, G., \& Sokoloff, P. (2006). A functional variant of the dopamine D3 receptor is associated with risk and age-at-onset of essential tremor. Proceedings of the National Academy of Sciences of the United States of America, 103(28), 1075310758.

Jenkinson, C. P., Cray, K., Walder, K., Herzog, H., Hanson, \& Ravussin, E. (2000). Novel polymorphisms in the neuropeptide-Y Y5 receptor associated with obesity in Pima Indians. International Journal of Obesity and Related Metabolic Disorders, 24(5), 580-584.

Jezior, D., Krajewska, M., Madziarska, K., Kurc-Darak, B., Janczak, D., Patrzalek, D., . . . Klinger, M. (2007). Posttransplant overweight and obesity: myth or reality? Transplant Proc, 39(9), 2772-2775.

Jonsson, E. G., Nothen, M. M., Grunhage, F., Farde, L., Nakashima, Y., Propping, P., \& Sedvall, G. C. (1999). Polymorphisms in the dopamine D2 receptor gene and their relationships to striatal dopamine receptor density of healthy volunteers. Molecular Psychiatry, 4(3), 290-296.

Kasiske, B. L., Snyder, J. J., Gilbertson, D., \& Matas, A. J. (2003). Diabetes mellitus after kidney transplantation in the United States. American Journal of Transplantation, 3(2), 178-185.

Keen-Rhinehart, E., Ondek, K., \& Schneider, J. E. (2013). Neuroendocrine regulation of appetitive ingestive behavior. Front Neurosci, 7, 213.

Kenny, P. J. (2011). Common cellular and molecular mechanisms in obesity and drug addiction. Nat Rev Neurosci, 12(11), 638-651.

Kenny, P. J., Voren, G., \& Johnson, P. M. (2013). Dopamine D2 receptors and striatopallidal transmission in addiction and obesity. Current Opinion in Neurobiology, 23(4), 535-538.

Killgore, W. D., \& Yurgelun-Todd, D. A. (2005). Body mass predicts orbitofrontal activity during visual presentations of high-calorie foods. Neuroreport, 16(8), 859-863.

Kringelbach, M. L., \& Berridge, K. C. (2010). The functional neuroanatomy of pleasure and happiness. Discov Med, 9(49), 579-587. 
Limosin, F., Romo, L., Batel, P., Ades, J., Boni, C., \& Gorwood, P. (2005). Association between dopamine receptor D3 gene BalI polymorphism and cognitive impulsiveness in alcohol-dependent men. Eur Psychiatry, 20(3), 304-306.

Lundstrom, K., \& Turpin, M. P. (1996). Proposed schizophrenia-related gene polymorphism: expression of the Ser9Gly mutant human dopamine D3 receptor with the Semliki Forest virus system. Biochemical and Biophysical Research Communications, 225(3), 1068-1072.

Martinez, D., Gil, R., Slifstein, M., Hwang, D. R., Huang, Y., Perez, A., . . AbiDargham, A. (2005). Alcohol dependence is associated with blunted dopamine transmission in the ventral striatum. Biological Psychiatry, 58(10), 779-786.

Michaelides, M., Thanos, P. K., Volkow, N. D., \& Wang, G. J. (2012). Translational neuroimaging in drug addiction and obesity. ILAR J, 53(1), 59-68.

Mokdad, A. H., Marks, J. S., Stroup, D. F., \& Gerberding, J. L. (2004). Actual causes of death in the United States, 2000. JAMA, 291(10), 1238-1245.

Moore, L., \& Gaber, A. O. (1996). Patterns of early weight change after renal transplantation. Journal of Renal Nutrition, 6(1), 21-25.

Need, A. C., Ahmadi, K. R., Spector, T. D., \& Goldstein, D. B. (2006). Obesity is associated with genetic variants that alter dopamine availability. Annals of Human Genetics, 70(Pt 3), 293-303.

Noble, E. P., Ozkaragoz, T. Z., Ritchie, T. L., Zhang, X., Belin, T. R., \& Sparkes, R. S. (1998). D2 and D4 dopamine receptor polymorphisms and personality. American Journal of Medical Genetics, 81(3), 257-267.

Olds, J., \& Milner, P. (1954). Positive reinforcement produced by electrical stimulation of septal area and other regions of rat brain. Journal of Comparative and Physiological Psychology, 47(6), 419-427.

Opland, D. M., Leinninger, G. M., \& Myers, M. G., Jr. (2010). Modulation of the mesolimbic dopamine system by leptin. Brain Research, 1350, 65-70.

Pandit, R., Luijendijk, M. C., Vanderschuren, L. J., la Fleur, S. E., \& Adan, R. A. (2014). Limbic substrates of the effects of Neuropeptide Y on intake of and motivation for palatable food. Obesity (Silver Spring).

Patel, M. G. (1998). The effect of dietary intervention on weight gains after renal transplantation. J Ren Nutr, 8(3), 137-141.

Pecina, M., Mickey, B. J., Love, T., Wang, H., Langenecker, S. A., Hodgkinson, C., . . . Zubieta, J. K. (2012). DRD2 polymorphisms modulate reward and emotion processing, dopamine neurotransmission and openness to experience. Cortex.

Pohjalainen, T., Rinne, J. O., Nagren, K., Lehikoinen, P., Anttila, K., Syvalahti, E. K., \& Hietala, J. (1998). The A1 allele of the human D2 dopamine receptor gene predicts low D2 receptor availability in healthy volunteers. Molecular Psychiatry, $3(3), 256-260$.

R Core Team. (2013). R: A language and environment for statistical computing. Vienna, Austria. Retrieved from http://www.R-project.org/

Reist, C., Ozdemir, V., Wang, E., Hashemzadeh, M., Mee, S., \& Moyzis, R. (2007). Novelty seeking and the dopamine D4 receptor gene (DRD4) revisited in Asians: haplotype characterization and relevance of the 2-repeat allele. Am J Med Genet B Neuropsychiatr Genet, 144B(4), 453-457. 
Roberts, M. D., Gilpin, L., Parker, K. E., Childs, T. E., Will, M. J., \& Booth, F. W. (2012). Dopamine D1 receptor modulation in nucleus accumbens lowers voluntary wheel running in rats bred to run high distances. Physiology and Behavior, 105(3), 661-668.

Roth, C. L., Hinney, A., Schur, E. A., Elfers, C. T., \& Reinehr, T. (2013). Association analyses for dopamine receptor gene polymorphisms and weight status in a longitudinal analysis in obese children before and after lifestyle intervention. BMC Pediatr, 13, 197.

Sabol, S. Z., Hu, S., \& Hamer, D. (1998). A functional polymorphism in the monoamine oxidase A gene promoter. Human Genetics, 103(3), 273-279.

Sander, T., Harms, H., Podschus, J., Finckh, U., Nickel, B., Rolfs, A., . . Schmidt, L. G. (1995). Dopamine D1, D2 and D3 receptor genes in alcohol dependence. Psychiatric Genetics, 5(4), 171-176.

Schinka, J. A., Letsch, E. A., \& Crawford, F. C. (2002). DRD4 and novelty seeking: results of meta-analyses. American Journal of Medical Genetics, 114(6), 643-648.

Schultz, W. (1998). Predictive reward signal of dopamine neurons. Journal of Neurophysiology, 80(1), 1-27.

Silveira, P. P., Portella, A. K., Kennedy, J. L., Gaudreau, H., Davis, C., Steiner, M., . . . Levitan, R. D. (2013). Association between the seven-repeat allele of the dopamine-4 receptor gene (DRD4) and spontaneous food intake in pre-school children. Appetite, 73C, 15-22.

Simon, G. E., Von Korff, M., Saunders, K., Miglioretti, D. L., Crane, P. K., van Belle, G., \& Kessler, R. C. (2006). Association between obesity and psychiatric disorders in the US adult population. Archives of General Psychiatry, 63(7), 824830 .

Small, D. M., Jones-Gotman, M., \& Dagher, A. (2003). Feeding-induced dopamine release in dorsal striatum correlates with meal pleasantness ratings in healthy human volunteers. Neuroimage, 19(4), 1709-1715.

Spreckelmeyer, K. N., Paulzen, M., Raptis, M., Baltus, T., Schaffrath, S., Van Waesberghe, J., . . . Grunder, G. (2011). Opiate-Induced Dopamine Release Is Modulated by Severity of Alcohol Dependence: An [(18)F]Fallypride Positron Emission Tomography Study. Biological Psychiatry.

Suzuki, K., Jayasena, C. N., \& Bloom, S. R. (2012). Obesity and appetite control. Exp Diabetes Res, 2012, 824305.

Swinburn, B. A., Caterson, I., Seidell, J. C., \& James, W. P. (2004). Diet, nutrition and the prevention of excess weight gain and obesity. Public Health Nutr, 7(1A), 123146.

Tang, D. W., Fellows, L. K., Small, D. M., \& Dagher, A. (2012). Food and drug cues activate similar brain regions: A meta-analysis of functional MRI studies. Physiology and Behavior.

Tomasi, D., \& Volkow, N. D. (2013). Striatocortical pathway dysfunction in addiction and obesity: differences and similarities. Critical Reviews in Biochemistry and Molecular Biology, 48(1), 1-19.

Tomkins, D. M., \& Sellers, E. M. (2001). Addiction and the brain: the role of neurotransmitters in the cause and treatment of drug dependence. CMAJ, 164(6), 817-821. 
Tunbridge, E. M., Huber, A., Farrell, S. M., Stumpenhorst, K., Harrison, P. J., \& Walton, M. E. (2012). The Role of Catechol-O-Methyltransferase in Reward Processing and Addiction. CNS Neurol Disord Drug Targets.

van den Ham, E. C., Kooman, J. P., Christiaans, M. H., Nieman, F. H., \& van Hooff, J. P. (2003). Weight changes after renal transplantation: a comparison between patients on 5-mg maintenance steroid therapy and those on steroid-free immunosuppressive therapy. Transpl Int, 16(5), 300-306.

Visentin, V., Prevot, D., De Saint Front, V. D., Morin-Cussac, N., Thalamas, C., Galitzky, J., . . . Carpene, C. (2004). Alteration of amine oxidase activity in the adipose tissue of obese subjects. Obesity Research, 12(3), 547-555.

Volkow, N. D., Fowler, J. S., Wang, G. J., \& Swanson, J. M. (2004). Dopamine in drug abuse and addiction: results from imaging studies and treatment implications. Molecular Psychiatry, 9(6), 557-569.

Volkow, N. D., Wang, G. J., \& Baler, R. D. (2011). Reward, dopamine and the control of food intake: implications for obesity. Trends Cogn Sci, 15(1), 37-46.

Volkow, N. D., Wang, G. J., Fowler, J. S., Logan, J., Gatley, S. J., Hitzemann, R., . . . Pappas, N. (1997). Decreased striatal dopaminergic responsiveness in detoxified cocaine-dependent subjects. Nature, 386(6627), 830-833.

Volkow, N. D., Wang, G. J., Fowler, J. S., Logan, J., Jayne, M., Franceschi, D., . . . Pappas, N. (2002). "Nonhedonic" food motivation in humans involves dopamine in the dorsal striatum and methylphenidate amplifies this effect. Synapse, 44(3), 175-180.

Volkow, N. D., Wang, G. J., Fowler, J. S., \& Telang, F. (2008). Overlapping neuronal circuits in addiction and obesity: evidence of systems pathology. Philosophical Transactions of the Royal Society of London. Series B: Biological Sciences, 363(1507), 3191-3200.

Volkow, N. D., Wang, G. J., Tomasi, D., \& Baler, R. D. (2013). The addictive dimensionality of obesity. Biological Psychiatry, 73(9), 811-818.

Volkow, N. D., Wang, G. J., Tomasi, D., \& Baler, R. D. (2013). Obesity and addiction: neurobiological overlaps. Obes Rev, 14(1), 2-18.

Wang, G. J., Smith, L., Volkow, N. D., Telang, F., Logan, J., Tomasi, D., . . Fowler, J. S. (2011). Decreased dopamine activity predicts relapse in methamphetamine abusers. Molecular Psychiatry.

Wang, G. J., Volkow, N. D., Logan, J., Pappas, N. R., Wong, C. T., Zhu, W., . . Fowler, J. S. (2001). Brain dopamine and obesity. Lancet, 357(9253), 354-357.

Wang, S. S., Morton, L. M., Bergen, A. W., Lan, E. Z., Chatterjee, N., Kvale, P., . . . Caporaso, N. E. (2007). Genetic variation in catechol-O-methyltransferase (COMT) and obesity in the prostate, lung, colorectal, and ovarian (PLCO) cancer screening trial. Human Genetics, 122(1), 41-49.

Wichers, M., Aguilera, M., Kenis, G., Krabbendam, L., Myin-Germeys, I., Jacobs, N., . . . van Os, J. (2008). The catechol-O-methyl transferase Val158Met polymorphism and experience of reward in the flow of daily life. Neuropsychopharmacology, 33(13), 3030-3036.

Willer, C. J., Speliotes, E. K., Loos, R. J., Li, S., Lindgren, C. M., Heid, I. M., . . . Hirschhorn, J. N. (2009). Six new loci associated with body mass index highlight a neuronal influence on body weight regulation. Nature Genetics, 41(1), 25-34. 
Wise, R. A. (2008). Dopamine and reward: the anhedonia hypothesis 30 years on. Neurotox Res, 14(2-3), 169-183.

Woodle, E. S., First, M. R., Pirsch, J., Shihab, F., Gaber, A. O., \& Van Veldhuisen, P. (2008). A prospective, randomized, double-blind, placebo-controlled multicenter trial comparing early (7 day) corticosteroid cessation versus long-term, low-dose corticosteroid therapy. Ann Surg, 248(4), 564-577.

Xia, Q., \& Grant, S. F. (2013). The genetics of human obesity. Annals of the New York Academy of Sciences, 1281, 178-190.

Yarnell, J. W., Patterson, C. C., Thomas, H. F., \& Sweetnam, P. M. (2000). Comparison of weight in middle age, weight at 18 years, and weight change between, in predicting subsequent 14 year mortality and coronary events: Caerphilly Prospective Study. Journal of Epidemiology and Community Health, 54(5), 344348.

Zhang, F., Fan, H., Xu, Y., Zhang, K., Huang, X., Zhu, Y., .. L Liu, P. (2011). Converging evidence implicates the dopamine D3 receptor gene in vulnerability to schizophrenia. Am J Med Genet B Neuropsychiatr Genet, 156B(5), 613-619.

Zhang, H., Li, S., Wang, M., Vukusic, B., Pristupa, Z. B., \& Liu, F. (2009). Regulation of dopamine transporter activity by carboxypeptidase E. Mol Brain, 2, 10.

Zhang, Y., Bertolino, A., Fazio, L., Blasi, G., Rampino, A., Romano, R., . . . Sadee, W. (2007). Polymorphisms in human dopamine D2 receptor gene affect gene expression, splicing, and neuronal activity during working memory. Proceedings of the National Academy of Sciences of the United States of America, 104(51), 20552-20557.

Ziauddeen, H., Farooqi, I. S., \& Fletcher, P. C. (2012). Obesity and the brain: how convincing is the addiction model? Nat Rev Neurosci, 13(4), 279-286. 


\section{APPENDIX A. GENOTYPE DATA COLLECTION}

The following describes the laboratory procedures followed to obtain genotype information from extracted DNA samples.

rs1799836

Context sequence:

AGAACACACTGGCAAATAGCAAAAG[T/C]GACACCATCTTTCTTCTAATCTGC $\mathrm{T}$

For rs1799836 TaqMan ${ }^{\circledR}$ assay the concentrations of reagents were as follows.

Master mix per sample (total of $25 \mu \mathrm{L}$ )

Water $13.75 \mu \mathrm{L}$

Buffer $2.5 \mu \mathrm{L}$

$\mathrm{MgCl}_{2} 2 \mu \mathrm{L}$

DNTP $4 \mu \mathrm{L}$

Forward primer $1.25 \mu \mathrm{L}$

Reverse primer $1.25 \mu \mathrm{L}$

Amp Gold Taq $0.125 \mu \mathrm{L}$

Thermal cycler conditions were as follows.

$95^{\circ} \mathrm{C}$ for 10 minutes.

$95^{\circ} \mathrm{C}$ for 1 minute.

$54^{\circ} \mathrm{C}$ for 30 seconds.

Repeat step \#2 x 35 .

Held at $10^{\circ} \mathrm{C}$.

rs1800497

Context sequence:

CACAGCCATCCTCAAAGTGCTGGTC[A/G]AGGCAGGCGCCCAGCTGGACGTC CA

For rs1800497 TaqMan ${ }^{\circledR}$ assay the concentrations of reagents were as follows.

Master mix per sample (total of $28 \mu \mathrm{L}$ )

Water $5.5 \mu \mathrm{L}$

PCR mix $6.25 \mu \mathrm{L}$

40x assay $0.3125 \mu \mathrm{L}$

DNA $1.1 \mu \mathrm{L}$

Thermal cycler conditions were as follows.

$95^{\circ} \mathrm{C}$ for 10 minutes.

$95^{\circ} \mathrm{C}$ for 15 seconds.

$60^{\circ} \mathrm{C}$ for 1 minute.

Repeat step \#2 x 40. 
rs4818

Context sequence:

GCCTGCTGTCACCAGGGGCGAGGCT[C/G]ATCACCATCGAGATCAACCCCGA CT

For the rs4818 TaqMan ${ }^{\circledR}$ assay the concentrations of reagents were as follows.

Master mix per sample (total of $28 \mu \mathrm{L}$ )

Water $5.5 \mu \mathrm{L}$

PCR mix $6.25 \mu \mathrm{L}$

40x assay $0.3125 \mu \mathrm{L}$

DNA $1.1 \mu \mathrm{L}$

Thermal cycler conditions were as follows.

$95^{\circ} \mathrm{C}$ for 10 minutes.

$95^{\circ} \mathrm{C}$ for 15 seconds.

$60^{\circ} \mathrm{C}$ for 1 minute.

Repeat step \#2 x 40.

rs6277

Context sequence:

TCTTCTCTGGTTTGGCGGGGCTGTC[A/G]GGAGTGCTGTGGAGACCATGGTGG $\mathrm{G}$

For rs6277 TaqMan ${ }^{\circledR}$ assay the concentrations of reagents were as follows.

Master mix per sample (total of $28 \mu \mathrm{L}$ )

Water $5.5 \mu \mathrm{L}$

PCR mix $6.25 \mu \mathrm{L}$

40x assay $0.3125 \mu \mathrm{L}$

DNA $1.1 \mu \mathrm{L}$

Thermal cycler conditions were as follows.

$95^{\circ} \mathrm{C}$ for 10 minutes.

$95^{\circ} \mathrm{C}$ for 15 seconds.

$60^{\circ} \mathrm{C}$ for 1 minute.

Repeat step \#2 x 40.

rs6280

Context sequence:

GCCCCACAGGTGTAGTTCAGGTGGC[C/T]ACTCAGCTGGCTCAGAGATGCCAT A

For rs6280 TaqMan ${ }^{\circledR}$ assay the concentrations of reagents were as follows.

Master mix per sample (total of $28 \mu \mathrm{L}$ )

Water $5.5 \mu \mathrm{L}$

PCR mix $6.25 \mu \mathrm{L}$ 
40x assay $0.3125 \mu \mathrm{L}$

DNA $1.1 \mu \mathrm{L}$

Thermal cycler conditions were as follows.

$95^{\circ} \mathrm{C}$ for 10 minutes.

$95^{\circ} \mathrm{C}$ for 15 seconds.

$60^{\circ} \mathrm{C}$ for 1 minute.

Repeat step \#2 x 40.

rs12364283

Context sequence:

TTACCAACTGTCCTCAGTTTGCCAG[A/G]TTCTGTGTCAGATTCAGAAGTCAC

A

For rs12364283 TaqMan ${ }^{\circledR}$ assays the concentrations of reagents were as follows.

Master mix per sample (total of $28 \mu \mathrm{L}$ )

Water $5.5 \mu \mathrm{L}$

PCR mix $6.25 \mu \mathrm{L}$

40x assay $0.3125 \mu \mathrm{L}$

DNA $1.1 \mu \mathrm{L}$

Thermal cycler conditions were as follows.

$95^{\circ} \mathrm{C}$ for 10 minutes.

$95^{\circ} \mathrm{C}$ for 15 seconds.

$60^{\circ} \mathrm{C}$ for 1 minute.

Repeat step \#2 x 40 .

rs4680

Context sequence:

CCAGCGGATGGTGGATTTCGCTGGC[A/G]TGAAGGACAAGGTGTGCATGCCT

GA

For the listed TaqMan ${ }^{\circledR}$ assays the concentrations of reagents were as follows.

Master mix per sample (total of $28 \mu \mathrm{L}$ )

Water $5.5 \mu \mathrm{L}$

PCR mix $6.25 \mu \mathrm{L}$

40x assay $0.3125 \mu \mathrm{L}$

DNA $1.1 \mu \mathrm{L}$

Thermal cycler conditions were as follows.

$95^{\circ} \mathrm{C}$ for 10 minutes.

$95^{\circ} \mathrm{C}$ for 15 seconds.

$60^{\circ} \mathrm{C}$ for 1 minute.

Repeat step \#2 x 40. 


\section{DRD4 VNTR}

For the DRD4 VNTR, the reaction mixture was as follows.

Master mix per sample $(25 \mu \mathrm{L}$ per sample)

Water $13.75 \mu \mathrm{L}$

Buffer/ $/ \mathrm{MgCl}_{2} 2.5 \mu \mathrm{L}$

DMSO $2 \mu \mathrm{L}$

DNTPs $4 \mu \mathrm{L}$

Forward primer $1.25 \mu \mathrm{L}$

Reverse primer $1.25 \mu \mathrm{L}$

Denville's Taq polymerase $0.125 \mu \mathrm{L}$

Thermal cycler conditions for the DRD4 VNTR were as follows.

$95^{\circ} \mathrm{C}$ for 30 seconds.

$70^{\circ} \mathrm{C}$ for 36 seconds.

$72^{\circ} \mathrm{C}$ for 40 seconds.

Repeat step \#1 x 40.

$72^{\circ} \mathrm{C}$ for 5 minutes.

Product was then run on a 2\% agarose gel at 200 volts for 1 hour and then stained with ethidium bromide. Subjects were genotyped using a comparison to a genetic ladder and control samples of known sequenced genotype

\section{Taq1A RFLP}

For Taq1A PCR the concentrations of reagents were as follows.

Master mix per sample (total of $28 \mu \mathrm{L}$ )

Water $13.75 \mu \mathrm{L}$

Buffer $2.5 \mu \mathrm{L}$

$\mathrm{MgCl}_{2} 2 \mu \mathrm{L}$

DNTP $4 \mu \mathrm{L}$

Forward primer $1.25 \mu \mathrm{L}$

Reverse primer $1.25 \mu \mathrm{L}$

Taq polymerase $0.125 \mu \mathrm{L}$

DMSO $3 \mu \mathrm{L}$

Thermal cycler conditions were as follows.

$95^{\circ} \mathrm{C}$ for 10 minutes.

$95^{\circ} \mathrm{C}$ for 1 minute.

$65^{\circ} \mathrm{C}$ for 30 seconds.

$72^{\circ} \mathrm{C}$ for 1 minute.

Repeat step \#2 x 35 .

Held at $10^{\circ} \mathrm{C}$.

A check of the PCR products was run on a 1\% agarose gel at 200 volts for 1 hour and then the successful PCR products were digested with TaqaI, 10 units ENZ, and $2 \mu \mathrm{L}$ of $10 \mathrm{x}$ buffer. After digestion, the products were run on a $2 \%$ agarose gel at 200 volts for 1 hour and then stained with ethidium bromide. Subjects were genotyped using a comparison to a genetic ladder and control samples of known sequenced genotype. 


\section{MAOA VNTR}

For the MAOA VNTR, the reaction mixture was as follows.

Master mix per sample (26 $\mu \mathrm{L}$ per sample)

Water $13.3 \mu \mathrm{L}$

Buffer $2.5 \mu \mathrm{L}$

$\mathrm{MgCl}_{2} 0.8 \mu \mathrm{L}$

DNTPs $4 \mu \mathrm{L}$

Forward primer $1.25 \mu \mathrm{L}$

Reverse primer $1.25 \mu \mathrm{L}$

Denville's Taq polymerase $0.125 \mu \mathrm{L}$

Thermal cycler conditions for the MAOA VNTR were as follows.

$95^{\circ} \mathrm{C}$ for 1 minute.

$55^{\circ} \mathrm{C}$ for 30 seconds.

$72^{\circ} \mathrm{C}$ for 1 minute.

Repeat step \#1 x 35 .

Held at $10^{\circ} \mathrm{C}$.

Product was then run on a 2\% agarose gel at 200 volts for 1 hour and then stained with ethidium bromide. Subjects were genotyped using a comparison to a genetic ladder and control samples of known sequenced genotype.

\section{SLC6A3/DAT1 VNTR}

Primer sets: Forward 5'-TGTGGTGTAGGGAACGGCCTGAG-3' and Reverse 5'CTTCCTGGAGGTCACGGCTCAAGC-3'

For the SLC6A3/DAT1 VNTR, the reaction mixture was as follows.

Master mix per sample (26 $\mu \mathrm{L}$ per sample)

Water $13.75 \mu \mathrm{L}$

Buffer $/ \mathrm{MgCl}_{2} 2.5 \mu \mathrm{L}$

DMSO $3 \mu \mathrm{L}$

DNTPs $4 \mu \mathrm{L}$

Forward primer $1.25 \mu \mathrm{L}$

Reverse primer $1.25 \mu \mathrm{L}$

Denville's Taq polymerase $0.125 \mu \mathrm{L}$

Thermal cycler conditions for the SLC6A3/DAT1 VNTR were as follows.

$95^{\circ} \mathrm{C}$ for 30 seconds.

$57^{\circ} \mathrm{C}$ for 36 seconds.

$72^{\circ} \mathrm{C}$ for 40 seconds.

Repeat step \#1 x 35 .

$72^{\circ} \mathrm{C}$ for 10 minutes.

Product was then run on a 2\% agarose gel at 200 volts for 1 hour and then stained with ethidium bromide. Subjects were genotyped using a comparison to a genetic ladder and control samples of known sequenced genotype. 


\section{APPENDIX B. INSTITUTIONAL REVIEW BOARD APPROVAL}

THE UNIVERSITY OF TENNESSEE

Health Science Center

Institutional Review Board

910 Madison Avenue, Suite 600

Memphis, TN 38163

Tel: (901) 448-4824

January 08,2013

Ansley Grimes Stanfill

College of Nursing

Department of Nursing

Alexander Building

Re: 12-02298-XM

Study Title: Dopaminergic genetic contributions to obesity in kidney transplant recipients

Dear Ms. Stanfill,

The Administrative Section of the UTHSC Institutional Review Board (IRB) has received your written acceptance of and/or response dated January 4, 2013 to the provisos outlined in our correspondence of December 21,2012 concerning the application for the above referenced project.

The IRB determined that your application is eligible for exempt review under 45CFR46.101(b)(4) in that it involves the study of existing data or other materials that are publicly available or the information will be recorded in a way that subjects cannot be individually identified. Informed consent is waived in accord with 45CFR46.116 (d). Your application has been determined to comply with proper consideration for the rights and welfare of human subjects and the regulatory requirements for the protection of human subjects. Therefore, this letter constitutes full approval of your application (version 1.1) for the above referenced study.

This study may not be initiated until you receive approval from the institution(s) where the research is being conducted.

In the event that volunteers are to be recruited using solicitation materials, such as brochures, posters, web- based advertisements, etc., these materials must receive prior approval of the IRB.

Any alterations (revisions) in the protocol must be promptly submitted to and approved by the UTHSC Institutional Review Board prior to implementation of these revisions. In addition, you are responsible for reporting any unanticipated serious adverse events or other problems involving risks to subjects or others in the manner required by the local IRB policy.

Sincerely,

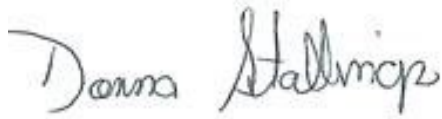

Signature applied by Donna L Stallings on 01/08/2013 06:28:33 AM CST

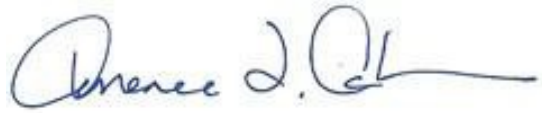

Signature applied by Terrence F Ackerman on 01/08/2013 06:30:12 AM CST

Donna Stallings, CIM

IRB Administrator

UTHSC IRB
Terrence F. Ackerman, Ph.D.

Chairman

UTHSC IRB 


\section{VITA}

Ansley Grimes Stanfill was born in 1981 in Palm Bay, Florida. She received a Bachelor's of Science in Neuroscience from Vanderbilt University in 2003, and a Bachelor's of Science in Nursing from Saint Louis University in 2007. She will graduate from the University of Tennessee Health Science Center on May 30, 2014. 